$\mathrm{Y}-12$

\section{OAK RIDGE \\ $Y-12$ \\ PLANT}

MALTH MARUETTA

\section{TECHNICAL BASIS FOR THE INTERNAL DOSIMETRY PROGRAM AT THE Y-12 PLANT}

J.C. Ashley

J.M. Barber

L.M. Snapp

J.E. Turner

March 2, 1992

Prepared by the Oak Ridge Y-12 Plant

$$
\begin{aligned}
& \text { COCEVVED } \\
& \text { MYY } 181933
\end{aligned}
$$

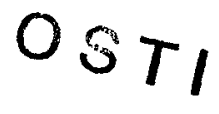

Oak Ridge, Tennessee 37831 operated by

Martin Marietta Energy Systems, Inc. for the

U.S. DEPARTMENT OF ENERGY

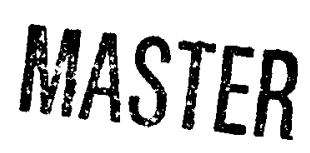

MANAGED BY

MARTIN MARIETTA ENERGY SYSTEMS, INC.

FOR THE UNITED STATES

DEPARTMENT OF ENERGY
DISTRIBUTION OF THIS DOCUMENT IS UNLIMITED

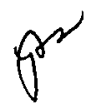




\section{DISCLAIMER}

This report was prepared as an account of work sponsored by an agency of the United States Government. Neither the United States Government nor any agency thereof, nor any of their employees, makes any warranty, express or implied, or assumes any legal liability or responsibility for the accuracy, completeness, or usefuiness of any information, apparatus, product, or process disclosed, or represents that its use would not infringe privately owned rights. Reference herein to any specific commercial product, process, or service by trade name, trademark, manufacturer, or otherwise, does not necessarily constitute or imply its endorsement, recommendation, or favoring by the United States Government or any agency thereof. The views and opınions of authors expressed herein do not necessarily state or reflect those of the United States Government or any agency thereof. 


\section{DISCLAIMER}

This report was prepared as an account of work sponsored by an agency of the United States Government. Neither the United States Government nor any agency Thereof, nor any of their employees, makes any warranty, express or implied, or assumes any legal liability or responsibility for the accuracy, completeness, or usefulness of any information, apparatus, product, or process disclosed, or represents that its use would not infringe privately owned rights. Reference herein to any specific commercial product, process, or service by trade name, trademark, manufacturer, or otherwise does not necessarily constitute or imply its endorsement, recommendation, or favoring by the United States Government or any agency thereof. The views and opinions of authors expressed herein do not necessarily state or reflect those of the United States Government or any agency thereof. 


\section{DISCLAIMER}

Portions of this document may be illegible in electronic image products. Images are produced from the best available original document. 
Y/DQ-40

\section{Technical Basis for the Internal Dosimetry Program At the Y-12 Plant}




\section{Table of Contents}

Chapter

1 Program Basis and Rationale $\ldots \ldots \ldots \ldots \ldots \ldots \ldots \ldots \ldots \ldots \ldots \ldots \ldots \ldots \ldots \ldots \ldots \ldots$

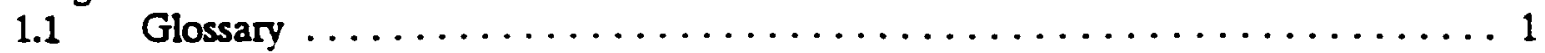

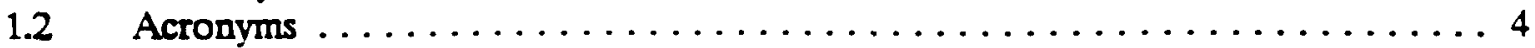

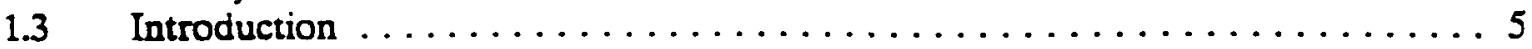

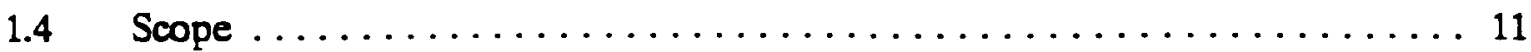

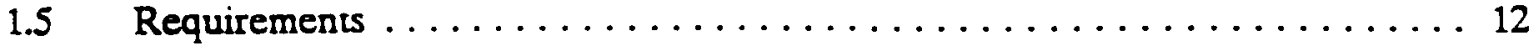

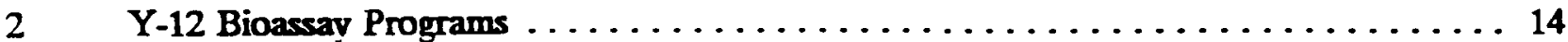

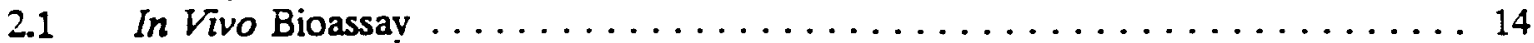

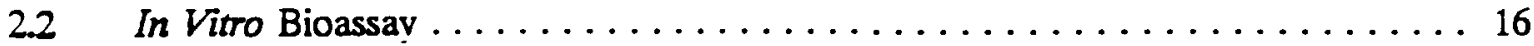

2.3 Basis for Key Elements of the Routine Bioassay

Programs . . . . . . . . . . . . . . . . . . . 18

23.1 The Biokinetic Model Used in Bioassay Program

Design . . . . . . . . . . . . . . . . . . . 18

23.2 Chronic Exposure at the Y-12 Plant ............... 19

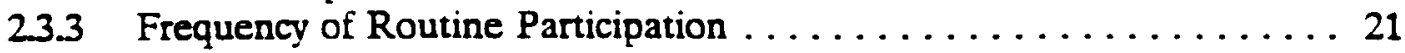

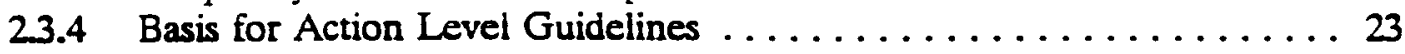

23.5 Basis for Participant Selection . . . . . . . . . . . . . 25

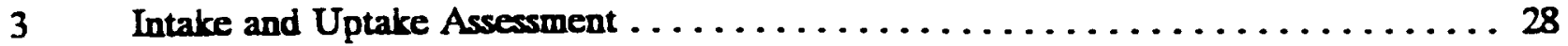

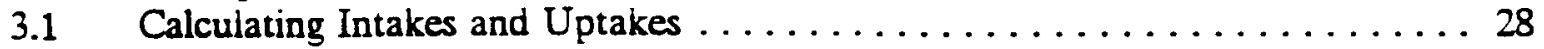

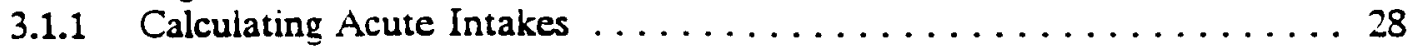

3.1.2 Calculating Acute Intakes Using Repentive

Bioassav Data . . . . . . . . . . . . . . . . . . . . 30

3.1.3 Calculating Chronic Intakes .................... 32

3.1.4 Calculating Acute Uptakes From Wounds . . . . . . . . . . . 34

3.2 Performing Intake and Uptake Assessments $\ldots \ldots \ldots \ldots \ldots \ldots$

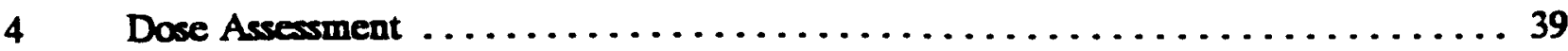

$4.1 \quad$ Intake and Dose Assessment . . . . . . . . . . . . . . . . . 39

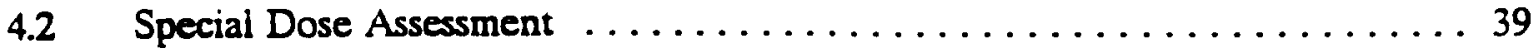

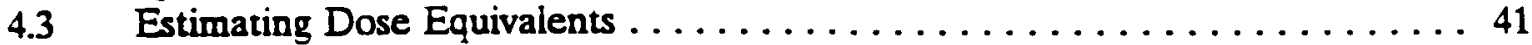

4.4 Reporting Dose Equivalent Estimates . . . . . . . . . . . . . . 42

$5 \quad$ Biokinetic Modek For Inhaled Uranium . . . . . . . . . . . . . . . . . 44

5.1 Metabolic Model For Inhaled Uranium Aerosols . . . . . . . . . . . . 44

5.2 Deposition and Retention in Respiratory System .............. 45

5.3 Systemic Retention and Excretion ................... 48

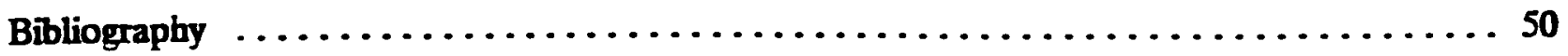




\title{
Chapter One
}

\author{
Program Basis and Rationale
}

\subsection{Glossary}

ACIION LEVEL GUIDEIINES: A reference value of a quantity that guides actions, such as the Investigation Level (IL), and derived investigation level (DIL).

ADMINISTRATIVE CONTROL ACTION LEVEL (ACAL): A value of organ or body content or excretion rate of radioactive materiais that indicates an intake which will resuit in an effective dose equivalent at the administrative control level (see site specific RADCON manual).

ADMINISTRATIVE CONTROL LEVEL-A challenging numerical dose constraint established at a level below the regulatory limits to administratively control and help reduce individual and collective radiation exposure.

AIRBORNE RADIATION AREA: Any area where airborne radioactive contamination concentrations greater than $10 \%$ of the derived air concentrations are present (or likely to be).

ACTIVITY MEDIAN AERODYNAMIC DIAMETER (AMAD): the diameter of a unit density sphere with the same terminal settling velocity in air as that of the aerosol particie whose activity is the median for the entire aerosol.

BASEIINE BIOASSAY: An appropriate radionuciide-specific bioassay measurement obtained from a bioassay program participant prior to beginning work with those nuclides.

BIOASSAY: The measurement of the amount or the concentration of radioactive material in the body or in biological material excreted or removed from the body.

BIOASSAY INCIDENT: An elevated bioassay resuit that indicates possible internal exposure greater than or equal to 100 millirem CEDE (result greater than DIL). A radiological incident investigation and a dose assessment will be performed for all bioassay incidents.

CONTROLIED AREA: Any area to which access is controlled in order to protect individuals from exposure to radiation and radioactive materials.

CONTAMINATION AREA: An area within a Controlled Area where radioactive contamination is present in excess of prescribed limits, or a high potential for contamination exists; where control measures are established to prevent or limit the contamination of personnel. equipment, or their environs, and where there is a possibility of an internal radiation exposure. 
DECISION LEVEI (DL): is the amount of material in a measurement result corresponding to a 5\% chance of a false positive. If the resuit of an analysis is above the decision level. material is deemed to be present.

\section{DEIECTION LEVEL: See Decision Levei}

DERIVED AIR CONCENTRATION (DAC): Quantity obtained by dividing the ALI for any given radionuclide by the volume of air breathed by reference man (ICRP 23) during one working year $\left(2400 \mathrm{~m}^{3}\right)$.

DERIVED INVESTIGATION LEVEL (DIL): A value of organ or body content or excretion rate of radioactive materiais that indicates an intake which will result in an effective dose equivaient of one investigation level ( $1 \mathrm{IL})$. At $\mathrm{Y}-12$, the IL is set at 100 millirem.

DIRECT (IN VIVO) BIOASSAY: The assessment of radioactive material in the body by detection of radiations emitted from materials contained within the body.

INTAKE: The amount of radioactive material taken into the body by inhalation. absorption through the skin, injection, ingestion or through wounds.

INTAKE RETENTION FRACTION (IRF): The fraction of an intake present in a mathematical "compartment" of a model which describes the biological translocation of material taken into the body, at some time " $\mathrm{t}$ " post intake. This compartment can correspond to a particular organ such as the lung, or to a compartment which represents either fecal or urinary excretion.

INVESTIGATION LEVEI, (II): The value of the committed effective dose equivaient from an intake(s) of radioactive material by a worker at or above which. for regulacory purposes. is regarded as sufficiently important to justify further investigation.

MINIMUM DETECTABLE ACTIVITY (MDA): The smallest amount of activity in a sample that will be detected with a $5 \%$ probability of false detection while accepting a $5 \%$ probability of false non-detection.

MINIMUM DETECTABLE (effective) DOSE: The minimum detectable committed (effective) dose equivalent associated with a bioassay program.

LAPEI AIR MONITORING. The monitoring of air for radioactive particles in the immediate vicinity of an individual radiation worker's nose and mouth. usually by a portable sampling pump and collection tube wom on the body. Lapel air monitoring is a special case of breathing zone air monitoring.

RADIOLOGICAL AREA: Any area within a controlled area where an individual can receive a dose equivalent greater than 5 millirem in 1 hour at $30 \mathrm{~cm}$ from the radiation source or any surface through 
which the radiation penetrates, or where airborne radioactive concentrations greater than $1 / 10$ of the derived air concentrations are present (or likely to be), or where surface contamination levels greater than those specified within Attachment 2 of DOE Order 5480.11 are present.

RADIOLOGICAL INCIDENT INVESTIGATION: Incident investigation (as defined in Procedure 70-XXX Radiological Incident Investigation (DRAFT), initiated due to a workplace or bioassay incident. The goal of this investigation is to determine the cause of the incident and suggest to appropriate management any corrective actions necessary to prevent future occurrences.

RADIATION WORKER: An occupational worker whose job involves operating radiation producing devices or working with radioactive matenal. or who is likely to be routinely occupationally exposed above 0.1 rem $(0.001 \mathrm{~Sv})$ per year.

REFERENCE MAN: A representative human model with the anatomical and physiological characteristics defined in the report of the ICRP Task Group on Reference Man (ICRP23).

REGULATED AREA: An area where the surface contamination levels are in excess of the guides specified in the Oak Ridge Operations Radiation Contamination Control Policy (ORO 1989).

RESPIRATORY PROTECTION LEVEL (RPL): Air concentration value at which respiratory protection is required. This value is identical to the Derived Air Concentration (DAC) listed in Attachment 1 of DOE Order 5480.11.

ROUTINE BIOASSAY: Bioassay measurements made on a predetermined periodic schedule.

SPECIAL BIOASSAY: One or more bioassay measurements performed on a regimen specified by an internal dosimetrist as follow-up to a potential internai intake.

TERMINATION BIOASSAY: Bioassay measurement performed whether upon termination of employment or upon the cessation of potential exposure to a specific nuclide for the purpose of documenting the retention of radioactive materials in the body due to occupational exposure.

UPTAKE: The amount of a radionuclide absorbed into extracellular fluids or taken up by the systemic compartment of the body (i.e., injections, direct respiratory tract transiocation, absorption from the GI tract, or absorption through the skin or through wounds in the skin).

WORKPLACE INCWEENT: Any abnormal event, trend, or condition, or uranium air sample results greater than the RPL indicating a confirmed or potential exposure to radioactive material which could result in an individual receiving 100 miiiirem CEDE. A radioiogicai incident investigation and a dose assessment will be performed for all bioassay incidents. 


\subsection{Acronyms}

$\begin{array}{lll}\text { ALI } & - & \text { Annual Limit on Intake } \\ \text { ACAL } & - & \text { Administrative Control Action Level } \\ \text { ALARA } & - & \text { As Low As Reasonably Achievable } \\ \text { AMAD } & - & \text { Activity Median Aerodynamic Diameter } \\ \text { ANSI } & - & \text { American National Standards Institute } \\ \text { BDMS } & - & \text { Bioassay Data Management System } \\ \text { CAM } & - & \text { Continuous Alpha Monitor } \\ \text { CINDY } & - & \text { Code for INternai DosimetrY } \\ \text { CFR } & - & \text { Code of Federal Regulations } \\ \text { CEDE } & - & \text { Committed Effective Dose Equivaient } \\ \text { DAC } & - & \text { Derived Air Concentration } \\ \text { DIL } & - & \text { Derived Investigation Level } \\ \text { DOE } & - & \text { Department of Energy } \\ \text { DU } & - & \text { Depleted Uranium } \\ \text { ES\&H } & - & \text { Environmental Safety and Health } \\ \text { EU } & - & \text { Enriched Uranium } \\ \text { GI } & - & \text { Gastro-Intestinal (Tract) } \\ \text { IAL } & - & \text { Initial Action Level } \\ \text { ICRP } & - & \text { International Commission on Radiological Protection } \\ \text { INDOS } & - & \text { INternal DOSimetry Code } \\ \text { IRF } & - & \text { Intake Retention Fraction } \\ \text { MDA } & - & \text { Minimum Detectable Activity } \\ \text { NCRP } & - & \text { National Council on Radiation Protection and Measurement } \\ \text { OSHA } & - & \text { Occupational Safety and Heaith Administration } \\ \text { QA } & - & \text { Quality Assurance } \\ \text { RADCON } & - & \text { RADiation CONtroi (Manual) } \\ \text { REIRS } & - & \text { Radiation Exposure Information Records System } \\ \text { RPL } & - & \text { Respiratory Protection Level } \\ \end{array}$




\subsection{Introduction}

Since the late 1940's, the Y-12 Plant in Oak Ridge, IN has been primarily a weapons facility operated by Union Carbide Corporation (until 1984) and Martin Marietta Energy Systems (since 1984) for the Department of Energy (DOE). DOE (and MMES) policy states that facilities should, where feasible, be designed and operated with engineered controls that prevent intakes of radioactive material by workers. While this policy is reasonable, in determining the feasibility of "total containment" for existing facilities not designed to provide this level of control, radiological toxicity shouid be considered in the overall risk benefit anaiysis. NCRP (NCRP87) states that .... "where work is with low toxicity radioactive materials such as uranium. process equipment and ventilation control systems are usually not designed for total containment...instead, air concentrations are controlled to acceptably low leveis." Although engineered controls are utilized to limit inhalation of uranium aerosols, low-level chronic inhalation of uranium remains the primary mechanism by which individuals are internally exposed to radioactive material at $Y-12$. The rates of chronic uranium intake at the Y-12 Plant are maintained As Low As Reasonably Achievable (ALARA), are detectable primarily because of state-of-the-art bioassay methods. and result in exposures which are only a fraction of DOE limits.

Internal dosimetry programs are required at facilities where individuals are likely to receive intakes greater than $2 \%$ of DOE limits (100 millirem CEDE), and as such, an internal dosimetry program is required at this facility. The objectives of an internal dosimetry program are to verify that workplace controls are adequate and are functioning correctly (unexpected intakes are not occurring) and to perform assessments for the intakes which occur. These objectives are met by constant air monitoring for uranium activity in areas where a potential for receiving 100 millirem CEDE exists, and providing bioassay monitoring (which consists of urine analysis, fecal analysis. and lung counting) for workers in these areas.

The technical basis for the air monitoring program at the Y-12 Plant is described in Y/DQ-29, "Technical Basis For Workplace Air Monitoring of Airborne Radioactive Material at the Y-12 Plant." 
YDQ-29 describes the technical basis for all retrospective. alpha continuous. and special air monitoring performed at the plant. Historically, the majority of the air sampling performed has been retrospective. Retrospective air monitoring utilizes sampling heads at fixed locations to determine the average airborne radioactivity level during some sampling period. This type of air monitoring is conducted in normally occupied areas whose quarterly average airborne radioactivity concentration has been greater than 2\% of the Derived Air Concentration (DAC). Continuous Alpha Monitoring (CAM) is performed in normally occupied areas where an individual is likely to receive. under typical conditions, an exposure to airborne radioactive material equivaient to $10 \%$ of the Annual Limit on Intake (ALI). Special monitoring includes low volume. high volume, and lapel air samplers. One of these types of special monitors is used in areas where retrospective or continuous air samplers are not in operation when any task (burning, grinding, welding, sweeping, etc.) is performed which is likely to generate radioactive material aerosois. Most of the air sample data collected is inappropriate for performing intake assessments. However, DOE Order 5480.11 (DOE88) states that air monitoring data should not be used for dose assessment. Instead of placing air sampiers so that they are likely to adequately reflect what is being breathed by an individual. these samplers are placed in locations (e.g., in airflow pathways close to and downstream from potential release points) where they are most likely to detect a failure in workplace controls.

Workplace controls are put in place to limit exposure to radionuciides. One of the primary purposes of air monitoring is to detect a failure in these workplace controls which could resuit in a significant human exposure. Procedure 50-66-HP-109 Radiological Incident Investigation Program For Potential Intemal Exposures specifies the actions to be taken by area health physics and internal dosimetry personnel whenever different types of radiological incidents occur. The intent of this procedure is to ensure that special bioassay and an investigation by area health physics personnel are performed for any incident with a potential for internal intake. For incidents invoiving air monitoring results the procedure specifies that any result which exceeds the respiratory nrotection level (RPL, or RPL multiplied by the protection factor of any respiratory protection worn) be followed by special bioassay, regardless of time spent in an area. Procedure 70-XXX Radiological Incident Investigation (DRAFT), to be issued in the near future, requires that area health physics personnel determine (e.g., by 
calculating an exposure in DAC-hours) if a special dose assessment (which will inciude special bioassay) should be requested when air sampling indicates that an internal exposure may have occurred. The draft procedure specifies radiological incident investigation roles and responsibilities for area operations supervisors, radiological engineers, area health physics personnel, and internal dosimetry personnel; for a variety of initiating events of radiological significance. Based on this procedure, a special dose assessment will be performed if it is likely someone has been exposed to the equivalent of 40 or more DAC-hours as required by RADCON (RC92). Section 4.2 of Chapter Four lists the events which initiate investigations for internal exposure. as well as the objectives of such investigations.

Air monitoring data can also be used to help select individuals for routine bioassay, and to determine the frequency with which they should participate. The primary purpose of the routine bioassay program at $Y-12$ is to help ensure that workplace controls are preventing significant intakes and maintaining chronic intake rates ALARA (and well below DOE limits). Individuals will be placed on a bioassay program if they normally work in areas where routine air monitoring (typically retrospective) is performed. For bioassay programs at facilities with chronic exposure. according to the NCRP (NCRP87), the bioassay frequency should be set so as to meet the following objectives:

1) to monitor the accumulation of radioactive material in exposed individuais. and

2) to ensure that significant depositions are detected.

When average airborne radioactive material concentrations are relativeiy low and there are no large "spikes." only a few bioassay measurements are required to verify workplace controis (objective number one). The DOE RADCON Manual states that routine bioassay measurements which indicate that an individual could have received 100 millirem CEDE shall be followed up with additional bioassay measurements. An individual chronically exposed to class " $Q$ " uranium (See § 2.3.1) at a rate which would resuit in them receiving 100 millirem/year, would be expected to excrete $12.5 \mathrm{dpm} /$ day (See $\S 2.3 .4$ ) of uranium activity in their urine. Personnel who work in areas with average airborne radioactive material concentrations less than $10 \%$ of the DAC and where no spike greater than $30 \%$ 
of the DAC has been observed ${ }^{1}$ will receive uranium urinaiysis measurements on an annual frequency (as recommended in NCRP 87), and the derived investigation level (DIL) for these measurement results will be set at $10 \mathrm{dpm} / \mathrm{day}$ (see below). For the purposes of this technical basis personnel on this uranium urinalysis program are denoted as Group One.

According to NCRP 87 when average airborne radioactive material concentrations exceed $10 \%$ of the DAC or spikes greater than $30 \%$ of the DAC can be expected. the frequency of routine bioassay should be based on ensuring that significant depositions do not go undetected (objective number two). To meet this objective it is necessary to establish frequencies and DILs which allow 100 millirem CEDE acute intakes to be detected. even in the presence of activity excreted due to chronic intake. For a 100 millirem acute inhalation of class " $Q$ " uranium at the midpoint ${ }^{2}$ between routine uranium urinalysis measurements collected on a quarterly frequency, approximately $10 \mathrm{dpm}$ would be expected in the measurement result following the intake (i.e., 45 days post intake). While a 100 millirem acute intake can be detected by uranium urinalysis for much longer than 45 days after exposure (See Figure 2-3), even for a DIL as "high" as $10 \mathrm{dpm} /$ day, a relatively large number of samples will require investigation due to low-level chronic intake (See § 2.3.3). Individuais who work in areas where average airborne radioactive material concentrations exceed $10 \%$ of the DAC or spikes greater than $30 \%$ of the DAC can be expected. will participate on the uranium urinalysis program on a quarterly frequency and the DIL will be set at $10 \mathrm{dpm} /$ day. The gicup of personnel participating on this program are designated as Group Two in this technical basis.

To lessen confusion concerning investigation levels, $10 \mathrm{dpm} / \mathrm{day}$ was chosen as the DIL for both the Group One and Group Two uranium urinalysis programs. When routine bioassay resuits exceed the DIL, a radiological incident investigation and special dose assessment (Chapter Four) are performed.

\footnotetext{
${ }^{1}$ Uniess there is reason to believe that radiologicai conditions wiil change rapidiy, air sample results for a period of one year will be used to evaluate areas. Also, the average and maximum air sampling results will be based on all of the samples in a general area (e.g., B-1 Wing 9212).

${ }^{2}$ The midpoint is the most likely time of intake between routine bioassay measurements based on statistics (ICRP 54).
} 
Currently, it is often impossible to make a distinction between Group One and Group Two personnel with the software (i.e., Y12URINAIYSIS) used to schedule individuals for bioassay. An action plan has been established to migrate to new software, called the Bioassay Data Management System (BDMS), where it will be possible to distinguish between Group One and Group Two personnel. For groups of people where this distinction is not possible. all individuals will participate on a quarterly frequency (most conservative). The migration to BDMS is projected to be complete by January 1, 1994. This migration will require that a considerable amount of information be compiled on each program participant (from their supervisors) and entered into the database by hand.

Based on the airborne radioactive material concentrations expected outside of airborne radiation areas, visitors who do not enter these areas have essentially no chance of receiving any significant uranium intake. Therefore, visitors should not be required to submit routine bioassay sampies during their visit uniess they plan to spend time in airborne radiation areas. However, if visitors are to spend time in such areas, they should collect a sample for uranium urinalysis before they enter the airborne areas and another sample before they leave the piant. Special bioassay and radiological incident investigations are performed whenever a bioassay result exceeds the decision level.

Some individuals involved in Environmental Restoration, Decontamination and Decommissioning or other work in which they have an exceedingly small chance of receiving a significant intake, receive uranium urinalysis as well as in vivo bioassay (see below) on an annual frequency to provide additional assurance that intakes are not occurring.

The low-level chronic intakes of uranium which occur at the Y-12 Plant are typically not detectable by the in vivo bioassay program. This program is maintained in order to meet the following objectives:

1) to assist in the rapid assessment of possible acute intakes, and

2) to survey for unexpected significant intakes of insoluble uranium which could escape detection by the in vitro program. 
As positive in vivo results are unexpected. any which occur are thoroughly investigated. There are two types of in vivo measurements, routine and special. Routine in vivo measurements are performed on an annual frequency for all individuals placed on a routine bioassay program (based on air monitoring). Special in vivo measurements are performed as soon after known incidents as possible. While the results from uranium urinalysis measurements can be delayed for some time after an incident, in vivo measurement results can allow an "upper boundary" on any possible acute inhalation of uranium to be established quickly. Additional details on this program. including an analysis of the maximum acute inhalation of uranium that could go undetected. are presented in Section 2.1 .

Baseine and termination in vivo and in vitro measurements are performed whenever an individual starts work in an area where they have the potential to be internally exposed (baseine), or when routine bioassay measurements are no longer necessary (termination). Special bioassay and radiological incident investigations are performed whenever a baseline bioassay result exceeds the decision level. Termination measurement results are compared with routine bioassay program DIIs to determine if follow-up actions are necessary.

Procedures covering all major aspects of the internal dosimetry program are either available, or scheduled to be developed (Draft RADCON Implementation Plan). Y-12 Plant operating procedures are required to be reviewed on at least a two year cycle. Quality Assurance (QA) surveillances on internal dosimetry procedures are performed on a regular schedule (schedules in In Vivo and In Vitro Program QA Plans). Also, Martin Marietta Energy Systems Safety and Health Organization regularly performs audits of site internal dosimetry programs. In addition to these internal audits. the Y-12 Plant internal dosimetry program is also audited by DOE Site Office. DOE Field Office, DOE Headquarters, Defense Nuclear Facility Safety Board, as well as Tiger Teams.

Management responsibilities for personnel radiation protection programs. inciuding internai dosimetry programs, are presented in Energy System Standard ESS-RP-101 Radiological Control. The Vice President for Compliance, Evaluations, and Policy is responsible for administration and oversight of this standard. Energy System Standard ESS-RP-102 ALARA for Radiation Protection Programs 
establishes specific management responsibilities for maintaining exposures As Low As Reasonably Achievable.

This manual is a "living" document that is responsive to the needs of the internal dosimetry programs at Y-12 It will be reviewed periodically to assure that the scientific foundations are current. Improvements to this manual will be based primarily on changes in DOE regulatory requirements, continual changes in the Y-12 Plant mission, changes in the methods used for internal dose assessment and dosimetry, or the need to incorporate information that has been found to be particularly helpful through experience gained by its use.

\subsection{Scope}

Since the beginning of plant operations, almost all work with radioactive materials has involved isotopes associated with uranium. enriched or depleted in $\mathrm{U}^{235}$. While limited quantities of isotopes of elements other than uranium (including those associated with the $T^{232}$ series and some transuranics from reprocessed uranium) are present, workplace monitoring (i.e., air sampling and contamination surveys) and process knowledge have established that internal exposure from these other isotopes is insignificant in comparison with uranium. While the changing piant mission may necessitate the consideration of internal exposure from otner isotopes at some point in time, only enriched and depleted uranium will be considered in this basis document.

The internal dosimetry technical basis common to each of the Energy System's internal dosimetry programs will be presented in the Martin Marietta Energy Systems Internal Dosimetry Technical Basis Manual which is under development. Only the portions of the internal dosimetry technical basis which may be unique to the Y-12 Plant will be considered in this manual.

This manual will present the technical basis of the routine in vivo and in vttro bioassay programs (choice of frequency, participant selection criteria, action level guidelines). Protocois for special bioassay will be presented in the chapters which describe the basis for intake, uptake, and dose 
assessment (Chapters Three and Four). A discussion of the factors which led to the need to develop a special biokinetic model for uranium at the Y-12 Plant, as well as a description of the model's basic parameters, are included in this document. The basis for this model is included in a separate document Y/DQ-39 "A Model for Uranium Lung Clearance at the Y-12 Plant". Resuits from some site characterization studies which have been performed are inciuded in that document. Additional site characterization efforts are under way, including a study being performed by the Inhaiation Toxicology Research Institute (ITRI). No data from that study is currently available.

Many different types of records are generated by the internal dosimetry programs. Procedures are available. or are being deveioped. to address all major aspects of these programs. Record requirements are included in current procedures and will be included in procedures still under development. Methods of generating, storing, archiving, and safeguarding records will not be presented in this document.

\subsection{Requirements}

DOE Notice N5480.6 mandates the implementation of the DOE Radiological Control (RADCON) Manual. Relative to prior guidance. RADCON places special emphasis on the neet tc instill more rigor and formality into the overall conduct of radiation protection operations. Several internal dosimetry program requirements are given in RADCON Chapter Five - Part 2 (Internal Dosimetry). Article 521 of RADCON Chapter Five specifies bioassay program requirements: The technical requirements for internal dosimetry and dose assessment are given. respectiveiy, in Article 522 and Article 523. Specific reporting requirements for the Annual Radiation Dose Summary to DOE are given in DOE Order 5484.1. DOE Order 5000.3B specifies DOE internal exposure occurrence reporting requirements.

Most of the internal dosimetry program requirements originaily presented in DOE 5480.11 have been either included in, or superseded, by DOE N5480.6 (RADCON). The requirements from DOE Order 5480.11 are due to be updated and published in the Code of Federal Regulations. Title 10, 
Part 835 (DRAFT), "Radiation Protection for Occupational Workers." Useful guidance in deveioping internal dosimetry programs is provided in the Implementation Guide (DOE91a) and Technical Manual (DOE91b) that are to accompany 10 CFR 835.

Criteria for the accreditation of radiobioassay service laboratories (in vivo and in vitro) are given in ANSI N13.30 (Draft, ANSI92). While this document is still in draft form, Y-12 bioassay programs seek to meet or exceed its requirements. This document specifies "good practices" for the management of bioassay programs. presents standardized methods for determining MDAs (so that laboratory capabilities can be compared) and Decision Leveis (to determine if activity is detected in a bioassay measurement. i.e., "positive"), and stipulates the minimum requirements for precision and bias at specified "Minimum Testing Leveis."

Martin Marietta Energy System's Safety and Health Organization specifies corporate policy with regard to internal dosimetry and bioassay programs in a series of Environmental Safety and Heaith (ES\&H) procedures. ALARA, bioassay monitoring, and dose assessment policy statements are given in numerous ES\&H standards such as ESS-RP-102. ESS-RP-104, ESS-RP-401, ESS-RP-402, and ESSRP-405. Air monitoring policy statements have been summarized in section 2.0. Chapter 1 of YDQ29. 


\section{Chapter Two \\ Y-12 Bioassay Programs}

\subsection{In Vivo Bioassay}

Four in vivo procedures at the Y-12 Plant specify the methods and requirements for performing routine lung count exams. Procedure Y50-66-HP-400 establishes the methods to be used in performing daily energy calibrations. full-width-at-half-maximum (FWHM) calibrations, background acquisitions, and performance (or source) checks, as well as instructions for performing lung count exams. Requirements and instructions for performing efficiency calibrations are presented in Procedure Y50-66-HP-401. Requirements which ensure that individuais are scheduled on the appropriate frequency and that appropriate follow-up actions are taken for missed appointments are given in Procedure Y50-66-HP-402. System baseline requirements, which establish how the system hardware and software should be set up and maintained for routine operations are given in procedure Y50-66-HP-403. In addition. record keeping requirements are specified in each of these procedures.

Lung counting is currently the only form of in vivo bioassay performed at the Y-12 Plant. However. the in vivo system has the capabilities required to perform in vivo analyses on organs such as the kidneys and bone whenever "standardized" phantoms for these organs become available.

A detailed discussion of $\mathrm{Y}-12$ in vivo software, including a functional verification of its analytical algorithms and results of a DOE Phantom Library intercomparison study and bias and precision evaluation (consistent with ANSI N13.30 requirements), is provided in Y/DQ-34 Verification of Y-12 Lung Counter Data Analysis Algorithms (Draft). For in vivo measurements. MDAs are "person dependent" (they depend primarily on the individual's chest-wail-thickness). Tynical MDAs are 0.2 $\mathrm{nCi}$ for U-235 and $3.0 \mathrm{nCi}$ for U-238. 
As stated in the introduction to this document, it is not possible to detect the low-level chronic intakes of uranium which represent the common mode of exposure at $Y-12$, using the $Y-12$ lung counter. Table 2-1 shows the minimum detectable "effective" dose equivalent for this system, based on typical MDAs, at various times post intake, for enriched uranium (EU) and depleted uranium (DU) intakes of both Class $Q$ and Class $Y$ uranium with an AMAD equal to $8 \mu \mathrm{m}$. The $8 \mu \mathrm{m}$ AMAD is based on particle size studies conducted on aerosols at the Y-12 Plant.

Table 2-1 Minimum Detectable Committed Effective Dose Equivaients for Lung Counting

\begin{tabular}{|c|c|c|c|c||}
\hline $\begin{array}{c}\text { Days Post } \\
\text { Acute Intake }\end{array}$ & $\begin{array}{c}\text { Q (millirem) } \\
\text { EU }\end{array}$ & $\begin{array}{c}\text { Q (millirem) } \\
\text { DU }\end{array}$ & $\begin{array}{c}\text { Y (millirem) } \\
\text { EU }\end{array}$ & $\begin{array}{c}\text { (millirem) } \\
\text { DU }\end{array}$ \\
\hline \hline 1 & 850 & 600 & 3300 & 2400 \\
\hline 2 & 1000 & 730 & 4000 & 2900 \\
\hline 3 & 1100 & 810 & 4500 & 3200 \\
\hline 4 & 1200 & 860 & 4700 & 3400 \\
\hline 5 & 1300 & 890 & 4800 & 3400 \\
\hline 6 & 1300 & 900 & 4900 & 3500 \\
\hline 7 & 1300 & 930 & 4900 & 3500 \\
\hline 14 & 1400 & 1000 & 5000 & 3600 \\
\hline 30 & 1700 & 1200 & 5000 & 3600 \\
\hline 90 & 3200 & 2300 & 5400 & 3900 \\
\hline 180 & 7000 & 5000 & 5900 & 4200 \\
\hline 360 & 16,000 & 11,120 & 7100 & 5100 \\
\hline
\end{tabular}

It is obvious from this table that the lung counting system is a very useful tool for the rapid assessment of possible acute intakes. The values in this table represent committed effective dose equivaients that should be detected with a $95 \%$ level of confidence. Committed effective dose equivaients that are approximately one half as large would have about a $50 \%$ chance of being detected. 
While the in vivo system can be useful in the evaluation of acute intakes which are still well below DOE limits. since any confirmed ${ }^{3}$ positive lung count result would most likely represent a committed effective dose equivalent in excess of 100 millirem, all positive results will be investigated (DIL = positive result). In addition to the Investigation Level (IL) and its corresponding DIL, an Administrative Control Action Level (ACAL) has been established which is intended to correspond to an intake (or intakes) of 1000 militirem. When an individual's bioassay resuit exceeds the ACAL. more aggressive actions are taken (See $\S 4.2$ ).

As can be seen from Table 2-1. under many circumstances a positive lung count measurement would correspond to a CEDE in excess of 1000 millirem. In the absence of specific knowiedge concerning a positive lung count result. which would indicate that the CEDE is less than 1000 millirem. actions based on the result exceeding the ACAL will be initiated.

\subsection{In Vitro Bioassay}

The in vitro program was designed based on (Draft) ANSI N13.30. Data management is described in Procedure Y/P65-7174, the chemical preparation for analysis is described in Procedure Y/P65-7173 and Y:P65-7i76, and the procedure used for counting in vitro samples is described in Procedure Y/P65-7177.

The Analytical Services Organization Bioassay Department provides bioassay capabilities for uranium in urine or feces. Sample preparation involves the addition of a $U^{232}$ tracer and several acid wash treatments (fecal samples are first ashed in a muffle furnace and digested in a stronger organic acid). After a sample has been wet ashed. a series of chemical precipitations and ion exchange resins are used to separate the uranium. Uranium isotopes are finaily coprecipitated with neodymium fluoride

\footnotetext{
${ }^{3} \mathrm{~A}$ lung count result is considered to be confirmed once surface contamination and detector background problems have been ruled out as the cause of the elevated result. A lung count measurement result will not normally be considered to be confirmed until it has been verified by one additional bioassay measurement.
} 
$\left(\mathrm{NdF}_{3}\right)$. The precipitate is captured on a $0.1 \mu \mathrm{m}$ filter, dried, and then mounted on a planchet for alpha spectroscopy.

Individuals requested to collect samples for uranium urinalysis are generally given bar-coded labels and asked to participate during a two-day break. These individuais receive training on where to pick up their sample collection kits, how to collect urine, what information to enter on the sample labels. how to follow the chain-of-custody procedure. and how to return the kit for anaiysis. A participant is normally required to collect either all voids during a twenty-four hour period. or. to collect their last void before retiring, all voids during the night, and the first void of the morning, on two consecutive days (simulated twenty-four hour sampies).

Spot uranium urinalysis samples (left at work) and fecal samples are sometimes requested after a known incident in which a significant acute exposure may have occurred. Individuals requested to collect these non-routine samples are given special collection kits and instructions. The follow-up bioassay measurement protocol after an incident is determined by an internal dosimetrist (See $\S 4.2$ ).

The methods of in vitro analysis allow uranium in urine and feces to be detected at environmental leveis. The laboratory detection ievels and a verification of the computer algorithms used for spectral analysis are to be presented in a document currently under development by the Analytical Services Organization. The detection levels are approximately $0.15 \mathrm{dpm}$ per sample for either urine or feces (based on a single void for feces or on all voids during a twenty-four hour period for urine). This is quite low in comparison with the $10 \mathrm{dpm} / \mathrm{day} \mathrm{DIL}$. In addition to the DIL an ACAL of 100 dpm/day has been established for uranium urinalysis.

Fecal sampling could be used to detect low-levels of exposure, just as uranium urinalysis is. However. given that both urine and fecal analysis provide essentially the same capabilities for detecting exposures to uranium at the Y-12 Plant, urinalysis has been chosen for primarily aesthetic reasons. 


\subsection{Basis for Key Elements of the Routine Bioassay Programs}

This section will attempt to provide justification for several key elements of the routine bioassay programs. These key elements inciude: the chronic exposure assumption. the frequency of participation, action level guidelines. and the criteria used in the selection of participants. In order to discuss these elements in detail, it will also be necessary to consider the biokinetic model used in the design of the bioassay programs.

\subsubsection{The Biokinetic Model Used in Bioassay Program Design}

To implement the requirements of DOE Order 5480.11 (1989), a very conservative bioassay program was adopted. Everyone spending one day or more per week in a radiological area (regardless of job assignment) was required to participate in a program in which most participates collected monthly samples for uranium urinalysis. Prior to beginning this new program. the analysis methods used for uranium in urine were upgraded (also to meet the new requirements). This upgrade resulted in a dramatic decrease in detection levels. Data collected by this new program demonstrate that chronic intake of uranium by individuals working in uranium processing areas is the most significant mode of uranium intake at the Y-12 Plant (See $\$ 2.3 .2$ ). The analysis of data collected from this program has allowed the current bioassay program to be developed. One of the features of the current program is a biokinetic model developed especially for exposures to uranium at the Y-12 Plant.

Prior to the new DOE Order (which implemented ICRP-30 methods of dosimetry), to be conservative and to simpiify the bioassay program. it was assumed that all uranium exposure was to the most restrictive class (insoluble) considered in DOE regulations. Although most exposures were known to be due to more soluble uranium compounds. the most restrictive material class was used. This most restrictive class was chosen because internal exposure controls made it possible, and it would have been extremely difficuit to ensure individuals were not exposed to both soluble and insoluble uranium. With the new methods of dosimetry used in DOE Order $\mathbf{5 4 8 0 . 1 1}$ (as evidenced by the five fold reduction in the uranium secondary air concentration limit), this practice was 
discontinued.

Since it is still difficuit to ensure exposed individuals will not receive intakes of several chemical forms of uranium, a new model was developed, using ICRP-30 methods of dosimetry, to better characterize the transiocation of the most insoluble uranium compounds likely to be inhaled at the Y-12 Plant.

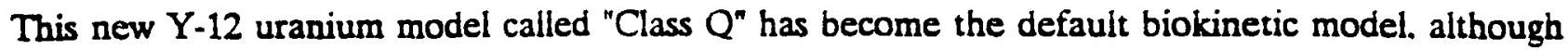
it is aiso very conservative for most uranium exposures at the plant. Additional details on this model are given in Chapter Five of this document and Y/DQ-39.

\subsubsection{Chronic Exposure at the Y-12 Plant}

About fifty thousand uranium urinalysis measurements have been collected since the "new" uranium urinalysis program went on-line in the fourth quarter of 1989. A review of this data indicates that chronic exposure is the most prevaient form of exposure at the plant.

Since individuals collect samples on their two-day break. they are normally out of their work area for less than 48 hours before they star collecting a sample. While thousands of routine resuits have exceeded the detection level (been "positive"), very few have contained as much activity as would be expected in the tirst few days following a 100 millirem CEDE intake. Out of 13.603 samples collected in 1992. 4088 exceeded the MDA of approximately $0.15 \mathrm{dpm}$. A 24-hour uranium urinalysis measurement collected the third day after a 100 millirem CEDE intake of Class $Q$ uranium would be expected to contain more than $170 \mathrm{dpm}$. Figure 2-1 summarizes the 1992 uranium urinalysis results which exceeded MDA. The vast majority of these resuits have only a fraction of the activity expected in the first few days following a significant acute intake. Figure 2.2 breaks down the uranium urinalysis results which exceeded $10 \mathrm{dpm} /$ day (DIL). With the exception of the first and last vaiues. the abscissa values on each of these figures represent the midpoint of a range of uranium urinaiysis results. In Figure $2-1$ these ranges are $0.5 \mathrm{dpm} / \mathrm{day}$, so the vaiue 0.75 represents the range of values $0.5<x \leq 1.0$. In Figure $2-2$ the ranges are 5 dpm/day, so the vaiue 17.5 represents the range of values $15<x \leq 20$ (every other abscissa value is displayed, e.g., 12.5 has been skipped). 
Although low-level chronic exposure is common the associated doses are relatively small. In 1991 (the last year for which dose equivalents are available at this time), only six individuais had CEDEs which exceeded 100 millirem (all of these were less than 200 millirem), with the majority of CEDEs less than $\mathbf{5 0}$ miliirem. As shown in the next two sections. the primary significance of this low-level chronic exposure is its effect on the choice of routine frequency and action leveis.

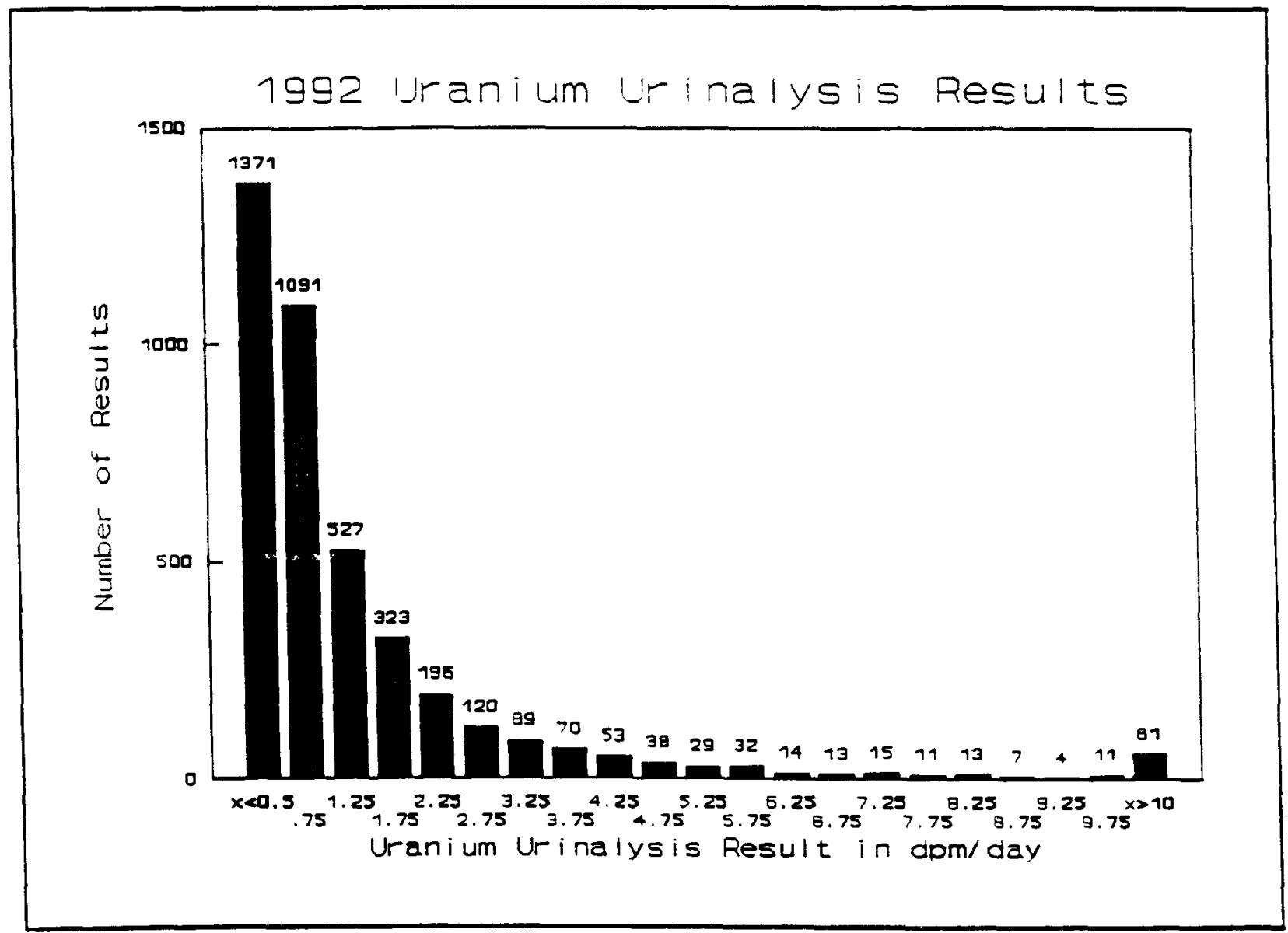

Figure 2-1 


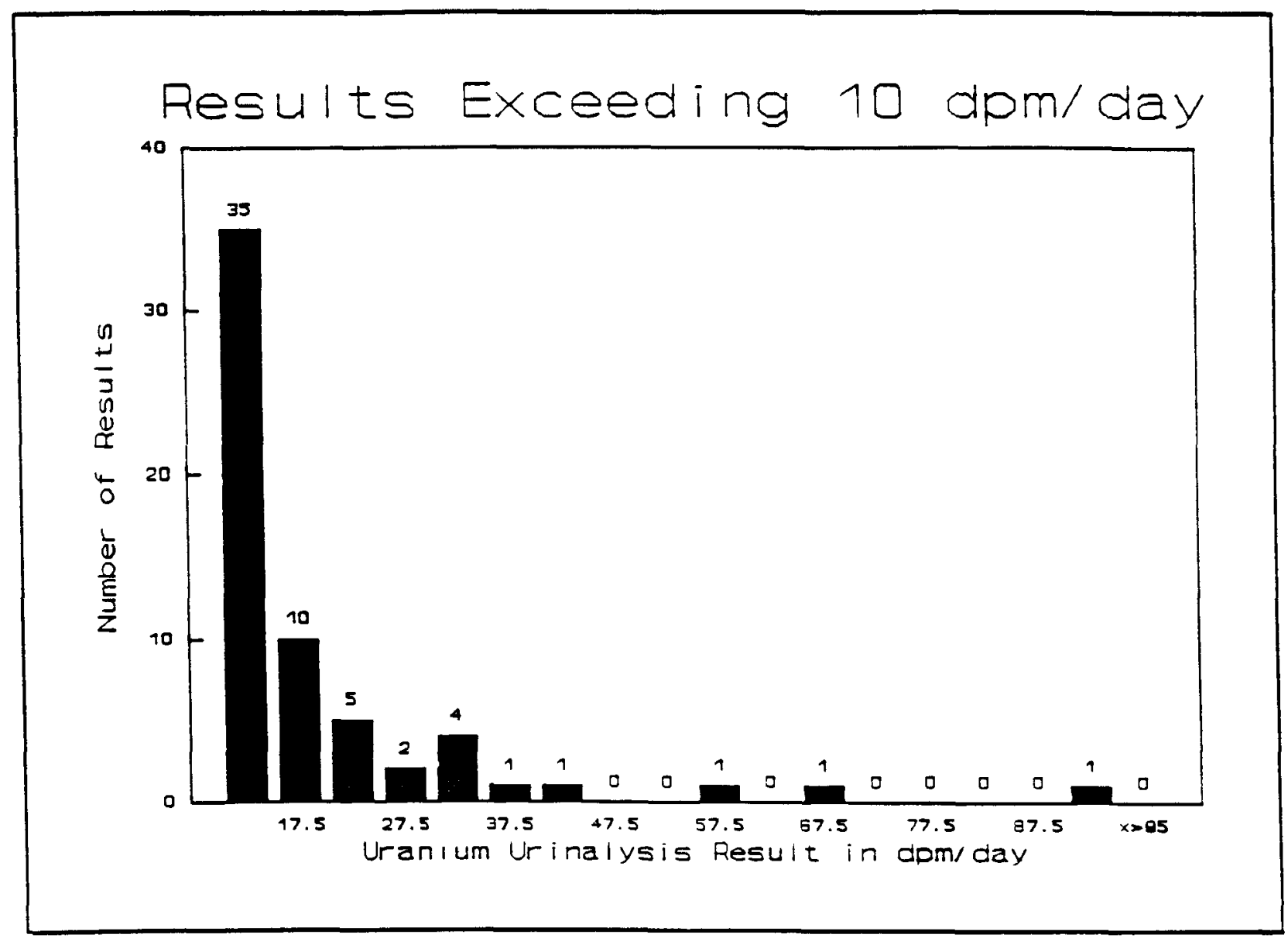

Figure 2-2

\subsubsection{Frequency of Routine Participation}

As stated in the introduction, at a facility with chronic exposure the bioassay frequency should be based on meeting the following objectives (NCRP87):

1) to monitor the accumulation of radioactive material in exposed individuals. and

2) to ensure that significant depositions are detected.

In cases where it must be considered, objective number two is typically more limiting. Air monitoring results are used to determine whether the frequency must be set based on meeting objective one or 
two. If air monitoring data indicate that workplace controis are preventing significant intakes, then relatively few bioassay measurements are required (as a final verification of this control). In most areas of the plant where air monitoring is performed. this is the case (See $\S 2.3 .5$ ) and bioassay measurements will be made on an annual frequency, which is the minimum frequency recommended by NCRP 87 (Group One).

However, if the goal of the bioassay program is to detect significant depositions (a significant acute intake), bioassay measurements must be scheduled on the frequency required to detect them (Group Two). This frequency will depend on factors such as the solubility/transportability of inhaled material. the type of bioassay which is to be performed. what is considered to be a "significant deposition", and how much activity can be expected to be in bioassay measurements due to chronic intake.

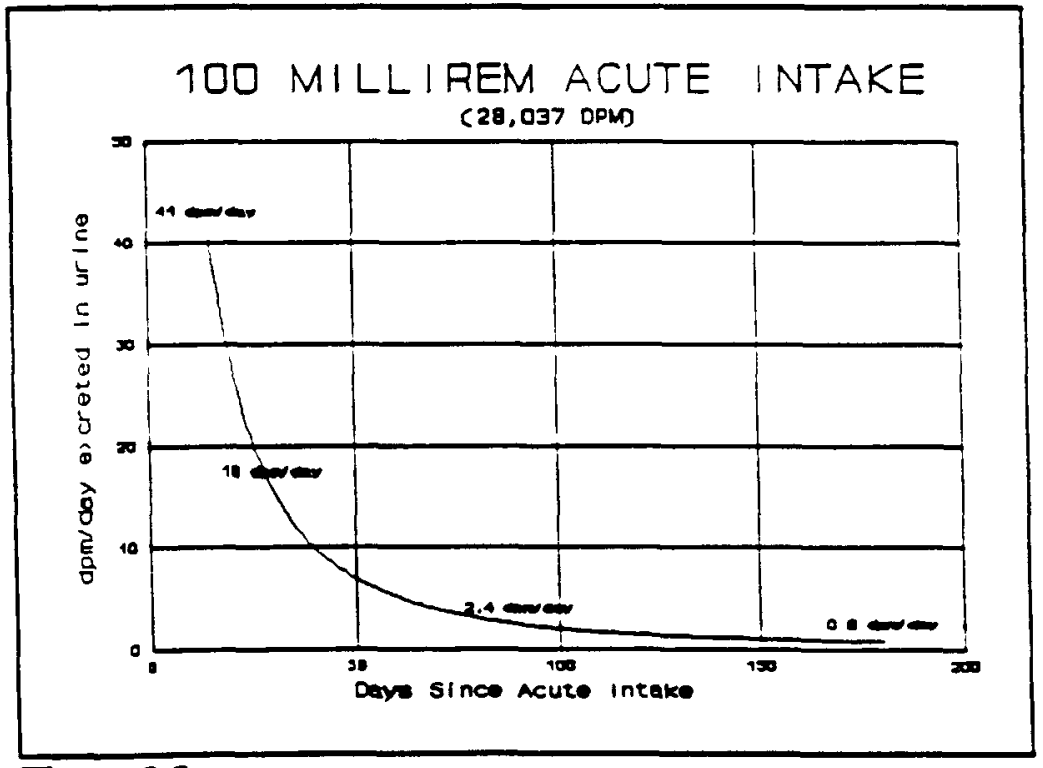

Figure 2-3
Assuming class $Q$ as the biokinetic model. and uranium urinalysis as the method of bioassay, it is still necessary to determine what will be called a "significant deposition" and how much activity can be expected due to chronic exposure. The DOE RADCON Manual states that routine bioassay measurements which indicate that an individual may have received 100 millirem CEDE shall be followed up with additional bioassay measurements.

In effect, a "significant deposition" has been defined as $2 \%$ of the DOE Radiation protection standard of 5000 millirem. .. Figure. 2-3 shows the activity expected in the urine, as a function of days since intake, of an individual who has had an acute intake corresponding to 100 millirem CEDE. Were it not for chronic intake it would be possible to detect a 100 millirem CEDE acute intake at more 
than six months after the original exposure $(\mathrm{DIL}=0.8 \mathrm{dpm}$ day, $\mathrm{MDA}=.15 \mathrm{dpm} / \mathrm{day})$. However, Figure 2-4 shows that during one month alone. the results of 630 individuals exceeded this value.

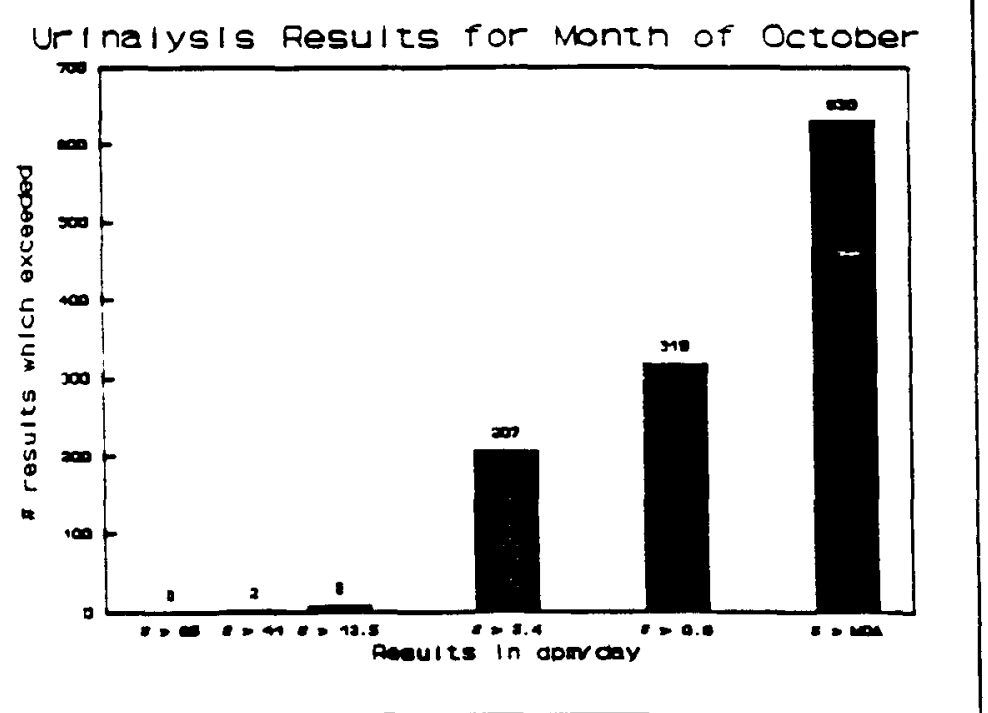

Figure 2-4
The level of chronic uranium intake is therefore too high for the DII to be set at this vaiue. Even with a three month frequency, 207 individuals would be expected to excrete uranium activity at a rate greater than or equal to a DIL of 2.4 dpm/day.

While it would be impractical to set the DIL at $2.4 \mathrm{dpm} / \mathrm{day}$, it is also impractical to require bioassay sampies more frequently than quarteriy (because of worker inconvenience and cost). Because of strong evidence indicating that significant (100 millirem CEDE) acute exposures are uniikely, a quarterly frequency will be established using a DIL of 10 dpm/day. With this DIL it is still possible to detect an acute intake corresponding to a CEDE of approximately 100 millirem if it occurs at statistically the most probable time between measurements, i.e., the midpoint. Based on this logic, it would be possible to miss a 400 millirem CEDE acute intake if it occurred on the day after the last bioassay measurement. This dose, though very unlikely, would still be well below DOE limits based on evidence already presented.

\subsubsection{Basis for Action Level Guidelines}

The basis fur the Gioup Two bioassay program DIL of 10 dpmiday was uescribed iñ the previous section. Once again using the 100 milirem "defauit" investigation ievei from RADCONy, the Group One DIL was determined by estimating the daily urinary excretion expected from an individual chronically exposed at a daily intake rate of 77 dpm which would result in a CEDE of 100 millirem 
per year. Figure 2-5 shows this pictorially. Under conditions of chronic exposure. the quantity of uranium excreted reaches a constant value after two or three years. However, this rate of excretion reaches over $90 \%$ of this equilibrium value $(\approx 12.5 \mathrm{dpm} / \mathrm{day})$ in only 90 days. In order to maintain consistent action leveis between the Group One and Group Two programs, a DIL of $10 \mathrm{dpm} /$ day was conservatively selected for the Group Two program. The ACALs were determined by simply muitiplying the DIls by 10 (1000 millirem instead of 100 millirem).

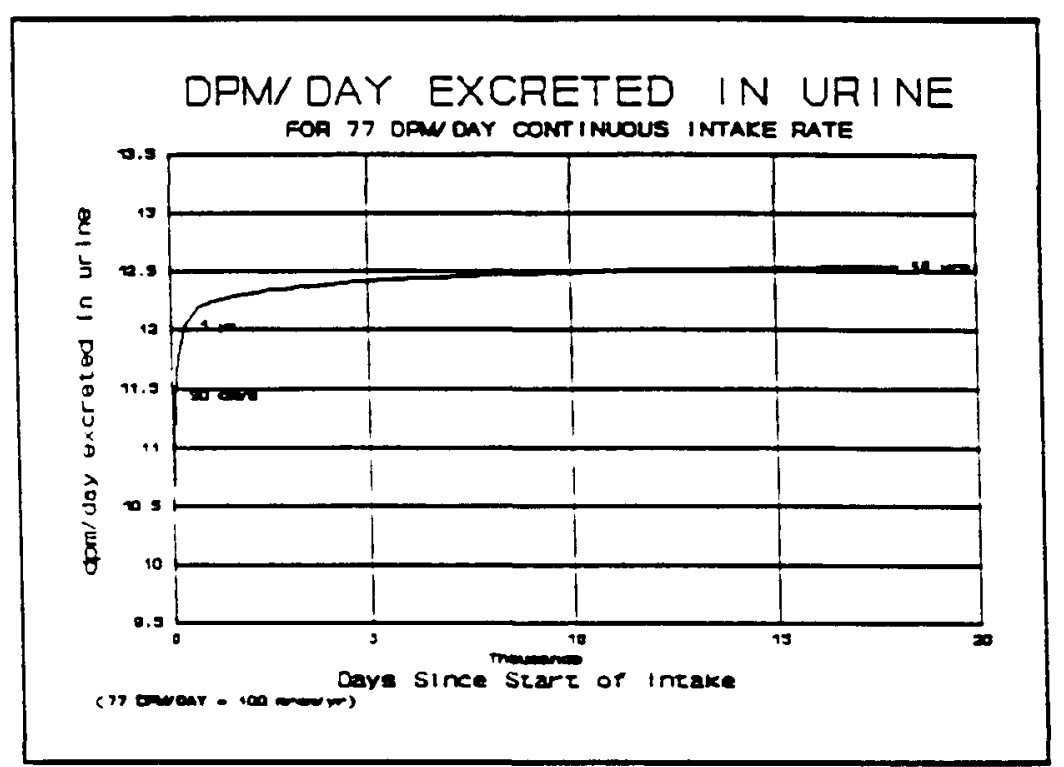

Figure 2-5

Much of the uranium processed at the Y-12 Plant is highly enriched in $U^{235}$. and for this material radiological toxicity is the major concern. However. significant quantities of depleted uranium are also processed at the plant. For internal exposure to depleted uranium. intake limits based on chemical toxicity (kidneys) can be more limiting than those based on radiological toxicity. The more soluble the uranium compound to which an individual is exposed. the more important chemical toxicity concerns become. However. highly soluble compounds of depleted uranium are not processed at $\mathrm{Y}-12$.

The American Conference of Governmental Industrial Hygienists (ACGIH68, ACGIH83) recommends a threshold limit yalue on the concentration of uranium in air of $0.2 \mathrm{mg} / \mathrm{m}^{3}$. Based on a standard breathing rate of $1.2 \mathrm{~m}^{3} / \mathrm{h}$. this corresponds to a daily intake rate of $2 \mathrm{mg}$ (approsimately $1400 \mathrm{dpm}$ ). Figure 2-6 shows that for a Group One program individual exposed continuously at the rate of $2 \mathrm{mg} / \mathrm{day}$, the quantity of uranium excreted reaches a constant value of almost $240 \mathrm{dpm}$ per 


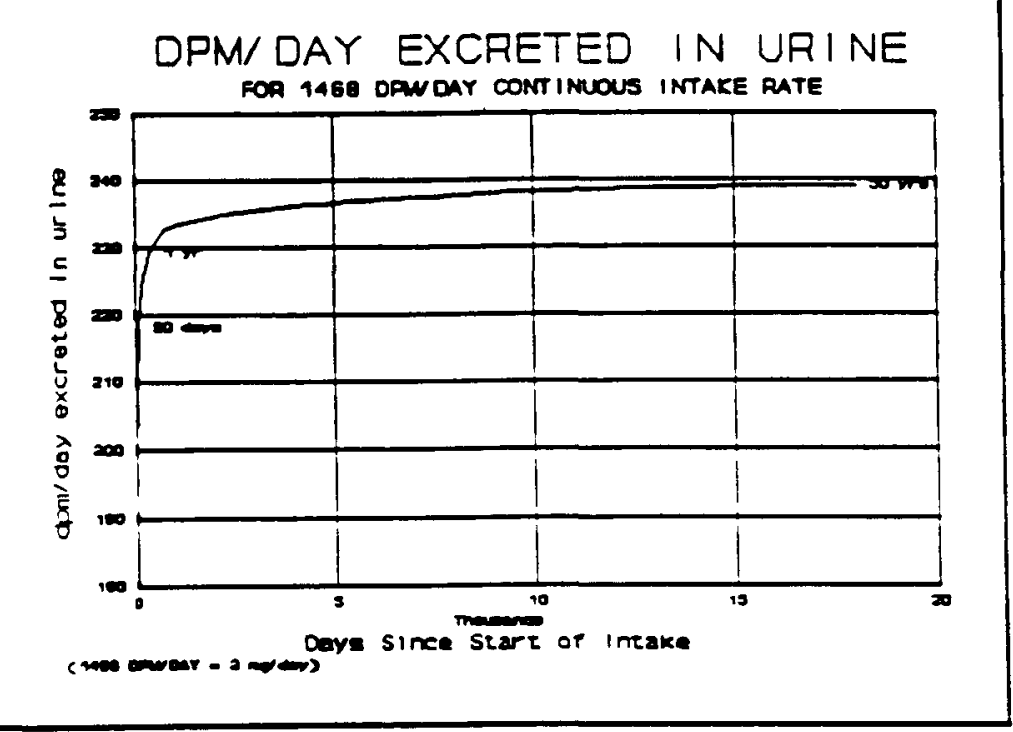

Figure 2-6 day, well above the $10 \mathrm{dpm} /$ day $\mathrm{DIL}$ based on enriched uranium. The DII for "uranium" is therefore more than adequate to detect elevated depleted uranium intake rates.

For acute exposure, the most restrictive intake limit is obtained using the nephrotoxic limit of 1.1 $\mu \mathrm{g} / \mathrm{g}$ of kidney (mass of kidneys $=$ $310 \mathrm{~g})$ found in $29 \mathrm{CFR} 1910.1000$ (OSHA74). This nephrotoxic limit corresponds to an acute intake of 22

mg of depleted uranium (approximately 16,000 dpm). Forty-five days after an intake of $22 \mathrm{mg}, 2.7$ $\mathrm{dpm}$ would be expected in the urine of the exposed individual. In depleted uranium areas where air monitoring resuits indicate that workers should be placed on a Group Two bioassay program. special bioassay and a radiological incident investigation will be performed whenever a routine depleted uranium urinalysis resuit exceeds $2.7 \mathrm{dpm}$ /day. There is only one Group Two area at the Y-12 Plant. and normally there are very few workers assigned to this area (typically less than ten).

\subsubsection{Basis for Participant Selection}

As stated in the introduction, individuals will be selected for routine bioassay program participation if they work in an area where routine air monitoring is performed (regulatory requirements for air monitoring and bioassay are both based on 100 millirem). The frequency with which they participate will depend on air monitoring results in their work area. Individuals will be requested to collect an annuai sample for uranium urinalysis, and scheduled for an annual lung count messuremest, if air monitoring results average $<10 \%$ of the DAC and the highest result in their work area is $<30 \%$ of the DAC. Individuals will be scheduled for routine lung count measurements and requested to collect 
quarterly samples for uranium urinalysis if air monitoring resuits average $\geq 10 \%$ of the DAC or the highest result in their area is $\geq 30 \%$ of the DAC.

The DAC based on class $\mathrm{Q}$ is $584 \mathrm{dpm} / \mathrm{m}^{3}$, so the values which correspond to $10 \%$ and $30 \%$ of the DAC are 58 and $175 \mathrm{dpm} / \mathrm{m}^{3}$, respectively. Out of $\approx 1400$ air samplers, results from 49 (based on one year of data) exceed one or both of these values. Results from these air samplers are presented in Figure 2-7. Based on these results. only individuals working in the uranium processing areas of 9212. 9206. and the Grit Blaster area of 9204-4. and in the Room 154 area of 9995 will be requested to participate on the quarterty bioassay program. 


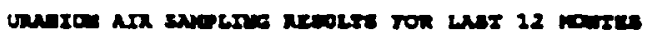

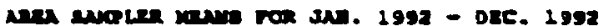

Anes or ave. marask

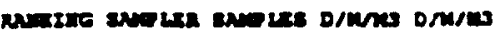

12002023

2127 a3s 233

$3125046 \quad 212$

135 $102 \quad 252$

$5212 \mathrm{a10} 230$

- $190 \quad 012 \quad 148$

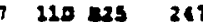

218 asj 239

- $227 \mathrm{E2} \quad 236$

$10 \quad 218025 \quad 219$

12110 106 24

$\begin{array}{llll}12 & 118 & 117 & 23\end{array}$

$13=18020 \quad 24$

1400138

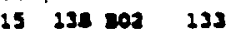

16 $135204 \quad 137$

17 135 297

$10210 \mathrm{M2} 240$

1) $210 \mathrm{D21} 245$

20026404248

$32 \quad 210$ nOS 290

$22 \quad 026 \quad 127 \quad 216$

$23115 \mathrm{Ba3} 213$

24190 nos 240

$2319 \%$ bos 140

28 138 361 146

$27 \quad 112020$

38210 ast 238

$25112 \quad 21243$

$30 \quad 11093028$

31 121 218 247

$32 \quad 222 \quad 022 \quad 24$

392380982146

34218034238

is 135 n19 146

36210026243

$3128 \mathrm{NOJ} 149$

3อ 128 \$46 24

J) $11 \% 000 \quad 241$

$40 \quad 110 \mathrm{mi1}$

$41234 \mathrm{DOS} 248$

12 1य $120 \quad 240$

$43 \quad 110=28 \quad 216$

14 I:A 103 245

(5) $118 \mathrm{22} 213$

$4110 \mathrm{B1} \quad 240$

$17220032 \quad 232$

4) $1: 2$ a1s 25

\section{5}

44.5

19.1

12.3

10.1

20.0

3s.

0.1

23.2

5.5

14.9

4.6

100.3

.6

6.0

23.8

10.2

26.2

0.6

3.

6.2

1.9

6.

3.1

1.6

1.2

12.2

20.6

8.0

15.3

2.7

16.6

7.3

7.3

2.3

9.6

6.6

2.0

1.3

22.0

2.9

4.5

32.3

1.3

2.9

13.5

12.3

4.4

12.2
Alte swoter ocsenterton

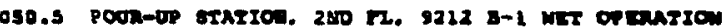

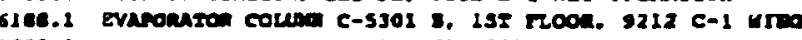

3382.2 TN TILTE R000. W. 135 PL. 9212 C-1 WILS

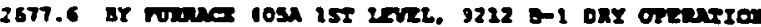

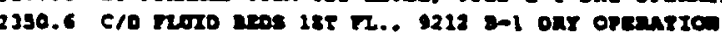

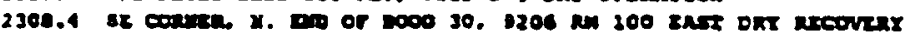

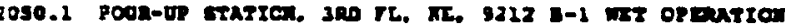

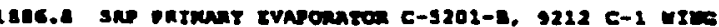

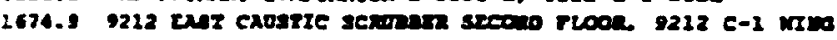

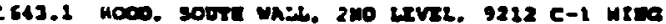

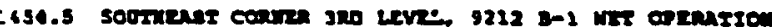

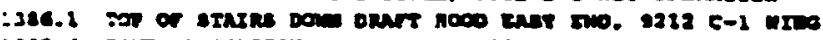

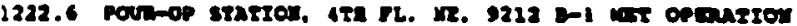

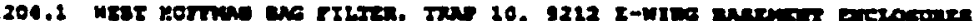

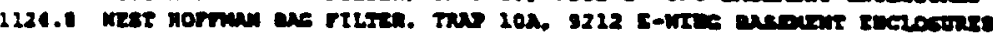

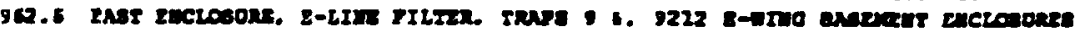

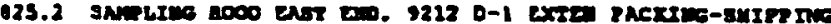

813.2 seom coemen, 320 PL.. 1212 M-1 wes ostatro

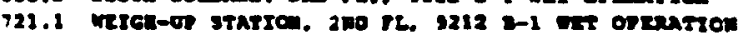

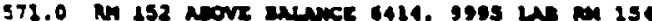

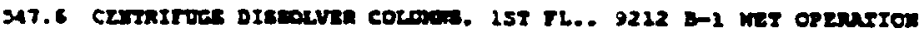

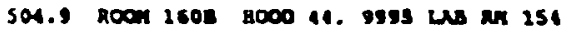

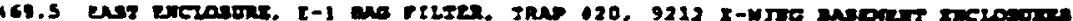

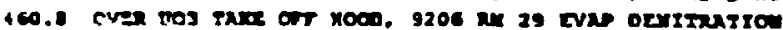

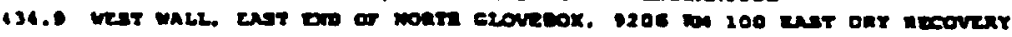

123.1 AI 7200 14. 9212 I-WDe cAstrite

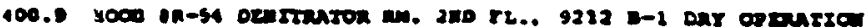

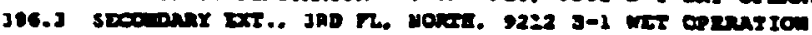

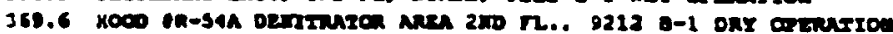

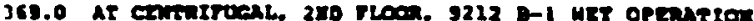

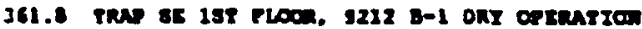

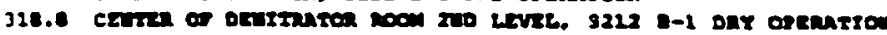

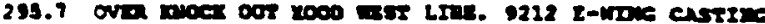

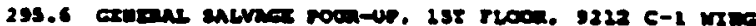

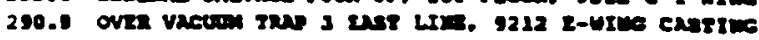

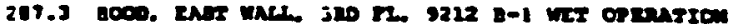

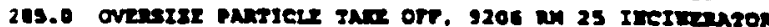

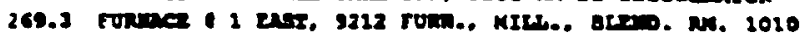

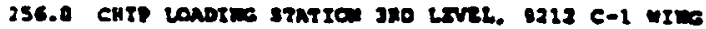

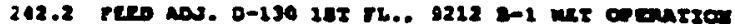

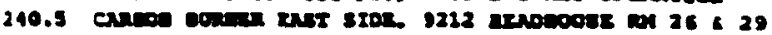

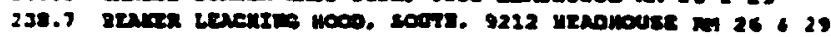

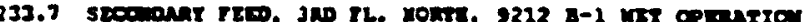

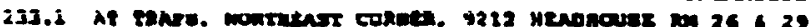

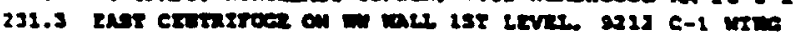

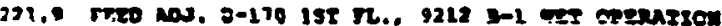

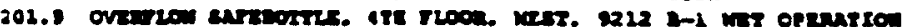

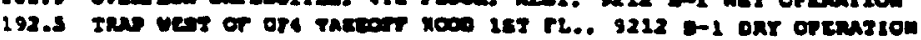

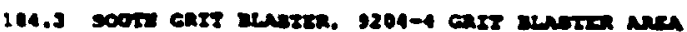

Figure 2-7 


\section{Chapter Three \\ Intake and Uptake Assessment}

\subsection{Calculating Intakes and Uptakes}

Intakes and uptakes (i.e.. from wounds) cannot be measured directly. but must be inferred from bioassay and/or air monitoring data. This inference requires a biokinetic model that provides a relationship between the bioassay and/or air monitoring data and intake. The biokinetic models used to describe the transiocation of uranium in the body are described in Chapter Five of this document and in Y/DQ-39.

Several different methods are available for estimating intakes. The "best" method depends on the available bioassay data, the available computing facilities, the type of intake. etc. While health physicists out in the field sometimes generate intake estimates using air concentrations, occupancy times, and DACs (e.g., to determine if special bioassay should be requested), final intake estimates are not based on these workplace monitoring data. Therefore, such methods will not be considered in this document.

All Y-12 dose estimates are generated from intake or uptake estimates. The methods used to generate special and routine intake estimates, and special uptake estimates. are described in this chapter. Once an intake or uptake estimate is available, it is easy to convert it into an estimate of dose equivalent (Chapter Five).

\subsubsection{Calculating Acute Intakes}

Most methods used to estimate acute intakes are similar to the one described in NUREG/CR-4884. "Interpretation of Bioassay Measurements." That document contains tables of acute inhalation and ingestion Intake Retention Fractions ( $I R F(t)$ 's) for various in vivo and in vitro bioassay measurement 
techniques. The values in these tables are based on biokinetic models and can be used to convert bioassay measurements into intake estimates. Given a resuit from a singie bioassay measurement at time, $t$, post intake, the intake is calculated by using the following equation:

$$
I=\frac{Y}{\operatorname{IRF}(t)}
$$

where:

$$
\begin{aligned}
\mathrm{I} & =\text { intake } \\
\mathrm{Y} & =\text { bioassay measurement result. and } \\
\operatorname{IRF}(\mathrm{t}) & =\text { intake retention fraction for the given bioassay measurement } \\
& \text { technique. }
\end{aligned}
$$

Biokinetic models assume that activity is continuously removed from the body of an exposed individual. In vitro $\operatorname{IRF}(t)$ values, based on these models. give the fraction of an initial intake expected to be collected in an excretion compartment (usually urine or feces) during some time period, typically one day. In order to use $\operatorname{IRF}(t)$ values with excretion data collected over time periods other than one day, it is necessary to normalize the activity (i.e., result) found in each sample so that it approximates the total amount of activity that would have been excreted in a day. Most of th: bioassay samples used in the estimation of intakes at $\mathrm{Y}-12$ (acute and chronic) are uraniure uricalysis samples whict have been collected over twenty-four hour periods; therefore, normalization is usually not required. However, bioassay samples are sometimes collected over periods of less than twenty-four hours. These samples are normalized as follows: sample mass is converted to volume by using the specific gravity of urine (ICRP23, $1.02 \mathrm{~g} / \mathrm{cm}^{3}$ ), the result is expressed as the ratio of activity to volume (dpm/liter), and the ratio is converted to dpm/24 hours by multiplying by the volume of urine excreted in one day by a "standard" person. From ICRP 23, a "standard" male excretes 1.4 liters of urine, while a "standard" female excretes 1 liter of urine, in a twenty-four hour period. For the sake of simplicity, it is normally assumed that a female also excretes 1.4 liters per day (conservative). For fecal samples, the activity in a single fecal void is taken to represent the total activity excreted by an individual in a day; no normalization is performed. 
The tables in NUREG/CR-4884 inciude acute $\operatorname{IRF}(t)$ values for the three standard lung clearance classes of uranium for a $1 \mu \mathrm{m}$ AMAD. IRF(t) values (including those for Class $\mathrm{Q}$ uranium) are normaily generated as part of an intake/dose assessment using either the INDOS (SK86) or DOSEXPRT (WA92) computer codes (called "expected $E_{v}(t)$," for urinary excretion, or "expected $E_{r}(t)$ ", for fecal excretion, "from a unit intake at $t=0$ ", in DOSEXPRT). A spreadsheet developed at Y-12 (LNGMDL1.WK3) can also be used to calculate IRF(t)'s; bowever, it is only used as a verification and development tool.

\subsubsection{Calculating Acute Intakes Using Repetitive Bioassay Data}

For many acute intakes. several bioassay measurements are made as part of the dose assessment (Chapter Four). With multiple bioassay measurements it is possible to generate an intake estimate based on a least-squares fit of the bioassay data to the biokinetic model used in the assessment. To perform such a fit it is necessary to make an assumption regarding the nature of the bioassay measurements' variance. There are three common assumptions regarding this variance, and hence there are three different fitting techniques which are commonly used to generate intake estimates based on repetitive bioassay measurements (SK86). The only fitting technique used to generate intake estimates at $\mathrm{Y}-12$ is the iteratively-weighted fit. With this fit. it is assumed that the variance in a measurement. $\sigma_{i}{ }^{2}$, is proportional to the measurement $s$ expectation value based on the biokinetic model (symbols were defined in Eq. 3-1).

$$
\sigma_{i}^{2} \propto I \times I R F_{l} .
$$

When this assumption is used. an intake may be estimated from the following equation:

$$
I=\frac{\sum_{i=1}^{N} Y_{l}}{\sum_{l=1}^{N} I R F_{l}}
$$

Intake estimates based on this algorithm are sometimes generated with INDOS. However, in order 
to allow easy entry of bioassay data and to provide better graphical capabilities, this method of intake estimation has also been implemented in a spreadsheet developed at the Y-12 P I ant (INCIDENT.WK3). By using this macro-driven spreadsheet. it is possible to generate intake estimates using Eq. 3-3 for Class D, $\mathrm{W}, \mathrm{Y}$, and $\mathrm{Q}$ and to graphically compare "expected" bioassay data based on these models with actual bioassay data (Figures 3-1 and 3-2). Such graphical representations are sometimes used to assist in choosing the appropriate model and to consider whether or not the default assumptions made in the intake assessment (e.g., intake date) are reasnnahle.
Acute Inhalation on $11 / 12 / 92$

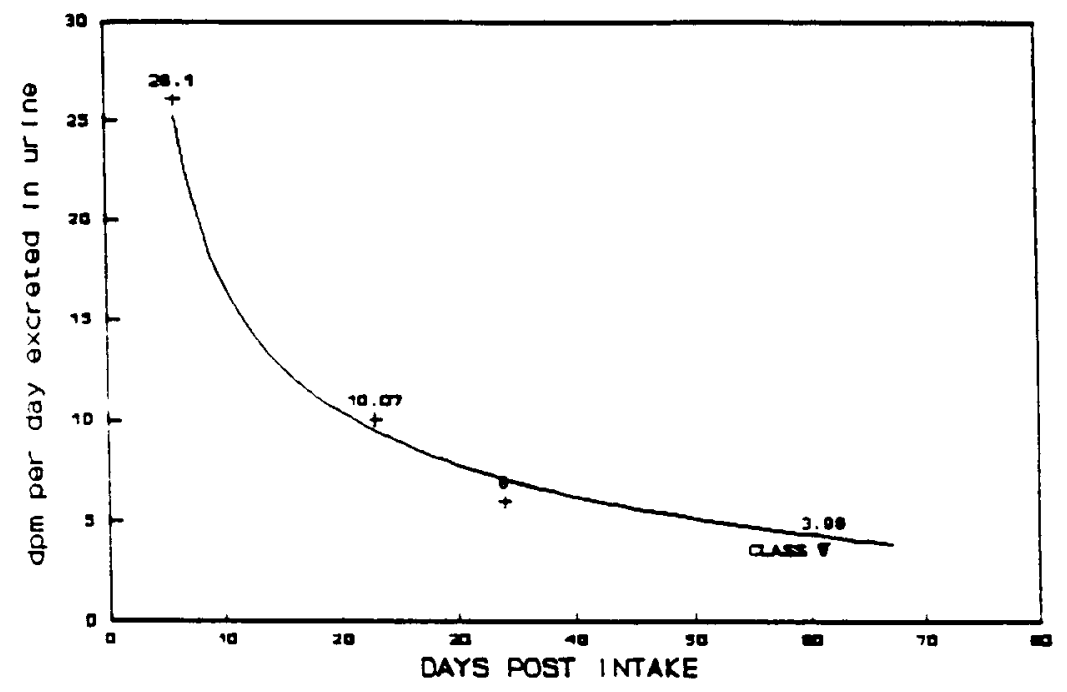

Figure 3-1

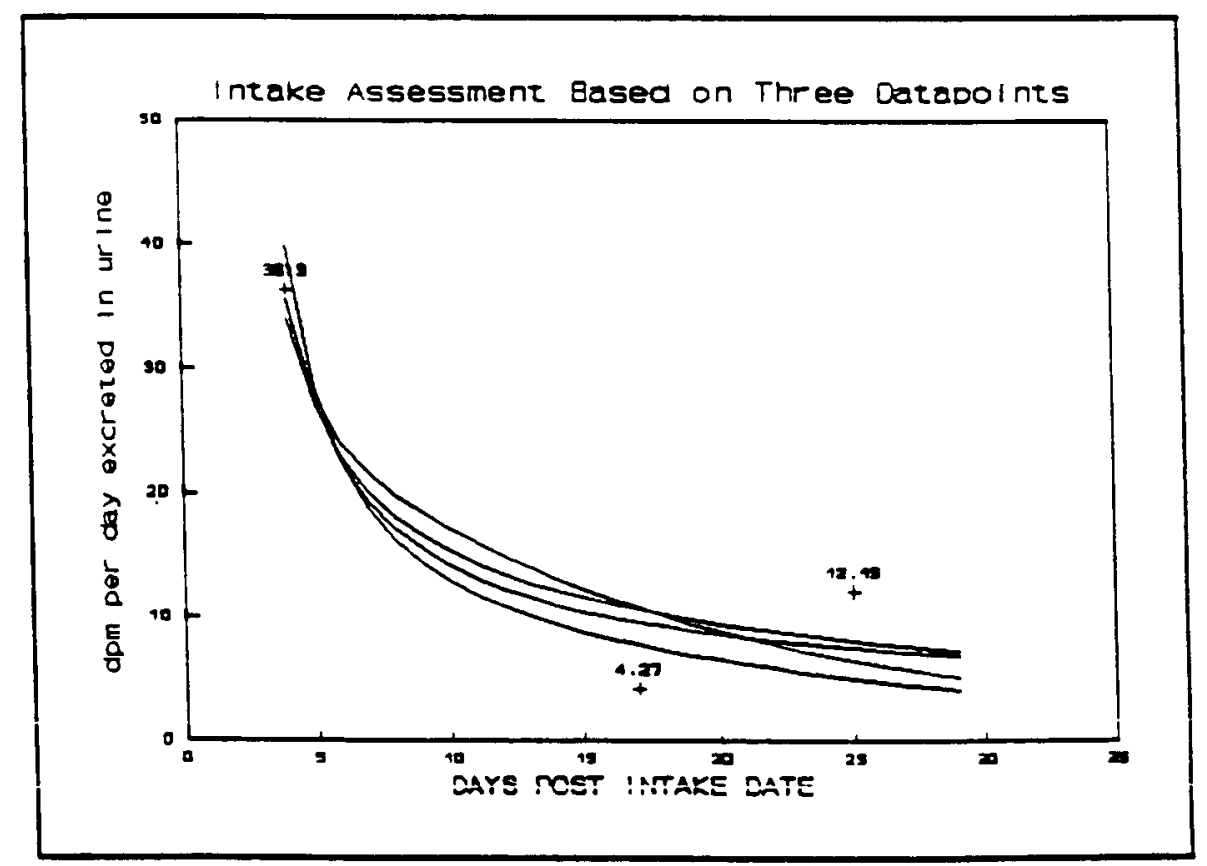

Figure 3-2 
Acute intake estimates are also generated by DOSEXPRT. With this computer code, intake estimates are generated for each bioassay measurement separately, using an algorithm identical to Eq. 3-1. DOSEXPRT then reports the average of these "single point" intake estimates as the final intake estimate.

All acute intake assessments are performed by using both DOSEXPRT and the INCIDENT.WK3 spreadsheet or INDOS. CINDY (which uses an algorithm similar to INDOS) is also used in some of these assessments (See §3.2).

\subsubsection{Calculating Chronic Intakes}

In order to estimate intakes due to chronic exposure (of particular interest at $\mathrm{Y}-12$ ), additional assumptions are required, and the calculations can become more complicated. The DOSEXPRT computer code is the primary tool used to analyze routine (chronic) bioassay data. While a number of codes (e.g., INDOS and CINDY) can be used to estimate chronic intake. DOSEXPRT has two features which make it especially weil suited for this task. DOSEXPRT can be run in batch mode. making it much easier to process the large quantity of routine bioassay data collected each year. The second feature is the algorithm DOSEXPRT uses for chronic intake estimates. To understand what makes DOSEXPRT's algorithm different. it is necessary to first consider what goes "into" a chronic intake assessment.

Section 3.1.1 described how to estimate an acute intake by dividing a bioassay measurement result (after normalizing if necessary) by an $\operatorname{IRF}(t)$ value. This $\operatorname{IRF}(t)$ value was obtained by using a biokinetic model to estimate the fraction of an acute intake of one unit of activin excreted or retained in a "compartment" (e.g., "lungs," "total urinary excretion," "total fecal excretion") as a function of time. A bioikinetic model can just as easily be used to predict the fraction of a continuous intaike of one unit of actrvitv per dav expected in a "compartment" at some point in time. It the broassay measurement result from an individual chronicallv exposed at a constant rate is divided by this "chronic" $\operatorname{IRF}(t)$ value (where $t$ is equal to the number of days since the beginning of intake), the 
quotient is the intake rate during the period. The total intake is calculated by multiplying this rate by the number of days in the chronic intake period. With computer codes such as INDOS and CINDY, only one chronic intake period (and therefore only one chronic intake rate for the period) can be considered in an single intake assessment. Multiple "routine" bioassay measurements can be used to estimate the "best fit" intake rate over the time period, but it still must be assumed that the rate remained constant during the period. Routine intake assessments are only performed once per year. so with INDOS and CINDY it is necessary to assume that the rate of chronic intake remains constant throughout the year.

With DOSEXPRT, the period between each bioassay measurement is treated as a separate period of chronic intake. (this period is referred to as a "panel"). DOSEXPRTs chronic intake assessment algorithm can be illustrated by considering the uranium urinalysis data of an individual chronicalily exposed. The code calculates an intake rate for the first intake period and then subtracts ("strips") the activity expected to be excreted due to daily intakes in this first "panel." from the remainder of the measurement results. It repeats the process (i.e., calculating a "net" intake rate for the next panei by subtracting contributions from all prior paneis. then using this "net" intake rate to "strip" the activity that will be excreted due to daily intakes in the panel from the rest of the measurement results) until a "net" intake rate has been calculated for each panel. This algorithm prevents the estimated intake rate for each panel after the first. from having a positive bias due to activity excreted because of intakes in a prior panel. In order to determine the quantity of activity that should be "stripped" from successive measurements due to continuous intake in a panel. values of "expected urinary excretion rate due to unit chronic intake" are calculated for each successive measurement based on

$$
E_{z}^{c}(t, T)=\int_{0}^{T_{c}} \dot{I}(\tau) E_{u}(t-\tau) d \tau,
$$

where:

$\mathrm{t}=$ time (day) of a future measurement (that is to be "corrected")

$\mathrm{T}_{e} \quad$ = time period over which chronic intake occurred (the "days" in a panel)

$\mathrm{I}(\tau)=$ intake rate during each instant $\tau$, of chronic intake (assumed constant)

$\mathrm{E}_{\mathrm{v}}(\mathrm{t}-\tau)=$ expected urinary excretion due to intake during $\tau$, at time $(\mathrm{t}-\tau)$. 
For intakes in each panel (except the last) the activity to be "stripped" from each measurement which follows is calculated by multiplying the "net" intake rate in the panel by the "expected urinary excretion rate due to unit chronic intake" for that following measurement (calculated from Eq. 3-4). The final intake estimate is equal to the sum of each panel's net intake rate multiplied by the number of days in that panel. A spreadsheet developed at the Y-12 Plant (CHRONIC.WK3) is used to independently verify intake estimates for selected cases as part of the verification of DOSEXPRT intakes.

\subsubsection{Calculating Acute Uptakes From Wounds}

Individuals occasionally receive internal uptakes due to wound contamination. These uptakes may be assessed by using methods similar to those used to assess intakes. There are two main differences between these types of assessment. With wound uptakes only the systemic retention portion of the appropriate biokinetic model is used (as opposed to the systemic retention function coupled with one or both of the GI Tract and Lung Models), and it may be desirable to model the uptake of activity to the systemic compartment from the wound site. Both INDOS and DOSEXPRT can be used to generate uptake estimates: however. only INDOS allows uptake from the wound to be modeled. Wound uptakes must be assessed in DOSEXPRT by usiug the "Injection" pathway. As the name implies. these uptakes are assumed to be "instantaneous." In reality, there is usually some time period over which material is released from a wound site into the blood stream.

In an uptake assessment, the haif-time for uptake of activity from the wound is estimated, and INDOS is used to produce an uptake estimate in a manner very much analogous to that used to generate an estimate of intake (multiple bioassay measurement results are fit to the systemic retention model using the iterative-weighted-fit option). Uptake estimates can also be used with the model to predict bioassay measurements which in turn cañ be graphicaliy compared with actual bioassay daca. This entire proceass can then be repeated. after "adjusting" the upraike naif-time from the wound. This process is typically repeated until a wound uptake half-time is selected which results in an uptake estimate that fits the data reasonably well. Figure 3-3 shows a plot of predicted bioassay 
data based on an uptake estimate, shown as "( )," and actual bioassay data. shown as "+". In this assessment, an uptake retention half-time of six days was selected (days post uptake are shown on the abscissa and excretion rates are shown in dpm/day on the ordinate).

Modeling the uptake half-time from the wound (instead of assuming that all activity from a wound site is instantaneously released) makes sense physically, and typically results in a more conservative uptake estimate. Whenever a wound uptake is expected (when contamination is detected in a wound) INDOS is used to estimate the uptake using this method. The computer code CINDY (see below) will be used to verify uptake estimates calculated with INDOS.

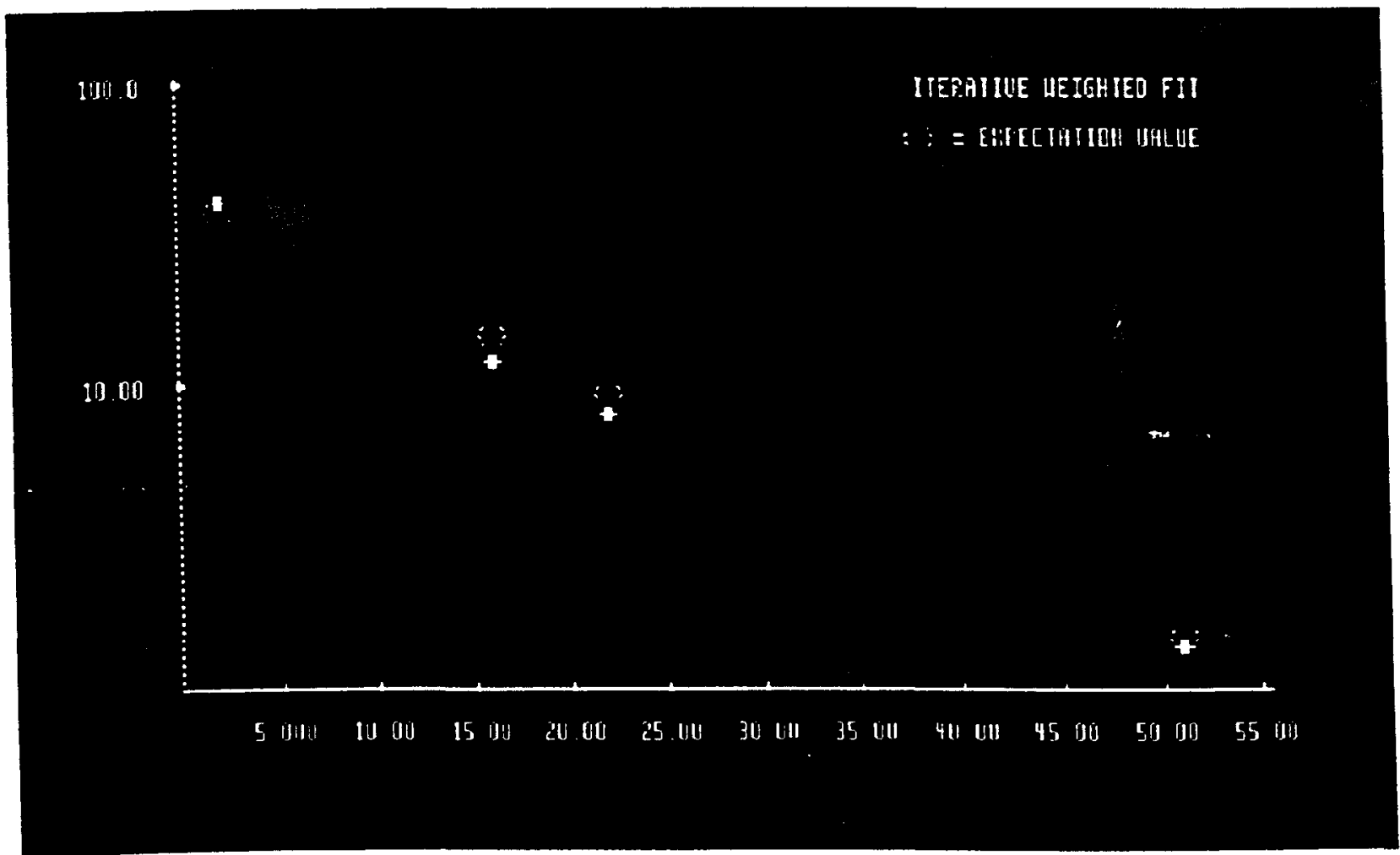

Figure 3-3 


\subsection{Performing Intake and Uptake Assessments}

Calculating intakes and uptakes based on bioassay data requires certain assumptions. Many of these have been described in the preceding sections on acute and chronic intake and acute uptake. Other important assumptions are discussed below.

Standard assumptions are typically used in initial intake assessments. These have been carefully selected to be conservative. yet reasonable. based on available information concerning the circumstances under which individuals are likelv to be exposed. The standard assumptions may be altered by the internal dosimetrist responsible for an intake assessment based on additional information that becomes available (during an incident investigation. for example). Justification for departing from standard assumptions must be included with the final intake estimate.

Intakes are assumed to occur by inhalation. Inhaled radioactivity is furthermore assumed to be transiocated according to the biokinetic model described in Chapter Five of this document and Y/DQ39. This model specifies the lung model. GI model. systemic retention function, and AMAD parameters that are to be used unless more specific knowledge concerning these parameters is known.

If an individual's uranium urinalysis resuts do not exceed the $10 \mathrm{dpm}$ day DIL it is assumed that he or she is being continuously (chronically) exposed to uranium. When routine uranium urinaiysis resuits exceed the DIL. a radiological incident investigation is initiated in order to determine if this person has recently received an acute intake. If no intake date is determined based on this incident investigation. it is assumed that an intake occurred at the midpoint between the individual's elevated resuit and the previous bioassay measurement. This leads to a more conservative (though usually less likely) intake estimate.

Acute intake estimates are routineiy generated with both DOSEXPRT and INCIDENT.WK3 or INDOS. The algorithm used by INCIDENT.WK3 and INDOS is normally considered somewhat "better" for acute intake estimates. However, as long as a reasonable model and intake parameters 
have been selected. the intakes predicted by the two computer codes are usually within $20 \%$ of one another. DOSEXPRT-generated intakes will be used for all acute intakes which will resuit in a CEDE of less than 100 millirem. if they differ from the INCIDENT.WK3 or INDOS intake by less than 50\%. If they differ by more than this amount for intakes which will resuit in a CEDE of less than 100 millirem. or by more than $25 \%$ for intakes which will result in a CEDE of greater than 100 millirem, an intake assessment will be performed using CINDY. Uranium intake estimates generated by CINDY using the "Ratio of the Means' method should be identical to those generated using the iteratively-weighted fit in INDOS (or INCIDENT.WK3). The larger of the INDOS or CINDY intake estimates will be used. All acute intake assessments must be reviewed by at least one other internal dosimetrist.

While the number of chronic intake assessments is too great to assess each by using an independent method, all intakes which will result in a CEDE greater than 100 millirem must be verified by a method independent of DOSEXPRT. The CHRONIC.WK3 spreadsheet was developed for this purpose. This spreadsheet uses chronic and acute $\operatorname{IRF}(t)$ values calculated with INDOS to generate intake estimates by using an algorithm similar to the one used by DOSEXPRT. This macro-driven spreadsheet accepts DOSEXPRT data files and automatically generates intake estimates which typically agree with DOSEXPRT intake estimates to within five percent. Routıne dose assessments are performed annually (in preparation for the REIRS report and the annual report to employees) and documentation of this verification is maintained in a separate file for each year. The intake assessment data from the routine intake (dose) assessments performed by DOSEXPRT must also be reviewed by more than one internal dosimetrist.

While several spreadsheets developed at the $Y-12$ Plant are sometimes used to assist in performing intake assessments, the final intake estimate from such an assessment must always be taken from a thoroughly tested and configuration-controlled software package. The three software packages that are used at Y-12 which meet these requirements are DOSEXPRT, CINDY, and INDOS. The source codes for INDOS, CINDY, and DOSEXPRT are not available at Y-12. Documentation (including DOSEXPRT input and output which shows models, parameters, and assumptions used) of all special 
intake assessments are prepared and stored with the incident investigation documentation. The version of DOSEXPRT used to generate final intake/dose assessment results for all chronic intakes. and most acute intakes, is stored with the intake and dose estimates in the database where they are maintained. 


\section{Chapter Four}

\section{Dose Assessment}

\subsection{Intake and Dose Assessments}

In this paper, the term intake assessment includes all of the assumptions. models, etc.. used to generate an intake estimate once all of the necessary data are available. The term dose assessment includes the intake assessment as weil as the steps taken to: obtain appropriate bioassay data, provide values for parameters needed in the intake assessment (in order to improve its accuracy by relying on fewer assumptions), and convert the intake into dose equivalents.

The steps necessary to complete a dose assessment vary from assessment to assessment. The standard assumptions used in intake assessments were presented in the preceding chapter. Defauit sampling protocols, sources of values needed to convert intake estimates to dose equivalents. and the manner in which calculated dose equivalents are reported are presented in this chapter.

\subsection{Special Dose Assessment}

If the results from a bioassay measurement exceed the DIL if workplace monitoring (e.g., air monitoring, personnel survey) indicates that an acute intake may have occurred. or if an incident/accident occurs (e.g., fire, ventilation failure) in which accidental intakes are likely; a radiological incident investigation and a special dose assessment are performed.

The level of effort associated with the investigation of an incident will be determined by Area Health Physics and Radiological Engineering, and will be commensurate with the incident's significance (magnitude of exposure. number of people potentially exposed. chronic exposure levels in the work area where the incident occurred, etc.). These investigations will normally seek to determine the cause of the incident (if it is unknown) and all of the individuals who may have been exposed. as well 
as provide any available workplace monitoring data (air samples. personnel surveys) and specific knowiedge concerning the nature of any intakes (intake date, type material) which may assist in the dose assessment.

In order to allow rapid decisions to be made in the early stages of incident investigation. two special bioassay measurement protocols have been established: one based on exposures expected to be $\geq$ ACAI and one based on exposures which are expected to be $\geq \mathrm{DIL}$. An internal dosimetrist must be notified of any situation which may require special bioassay. The internal dosimetrist is responsible for establishing the special bioassay measurement protocol and may modify the "generic" protocois below.

If an exposure approaching the speciai control level of 1000 millirem is expected due to a workplace incident, a routine bioassay result exceeds the ACAL, or a special bioassay measurement indicates an intake of 1000 millirem CEDE (based on an initial intake/dose estimate), the affected individual will be restricted from areas where he or she may receive additional internal exposure and follow-up bioassay measurements will be performed according to the following protocol.

1) A spot uranium urinaiysis measurement will be collected (in the case of a known incident/accident. the sampie will be collected a minimum of four hours after the suspected intake).

2) A special lung count will be performed as soon as possible after suspected intake.

3) A fecal sample (single fecal void) will be collected (in the case of a known incident/accident. the sample will be collected a minimum of 24 hours after the suspected intake).

4) A twenty-four hour uranium urinalysis sample will be collected following the normal sampling protocol (sample collected at home).

If an exposure which will likely result in 100 millirem CEDE is expected due to a workplace incident. a routine bioassay result exceeds the DIL, or a special bioassay measurement indicates an intake of 100 millirem CEDE (based on an initial intake/dose estimate), follow-up bioassay measurements will be performed according to the following protocol. 
1) A special lung count will be performed as soon as possible after suspected intake.

2) A twenty-four hour uranium urinalysis sample will be collected following the normal sampling protocol (sample collected at home).

For bioassay incidents in which a routine bioassay measurement exceeds the ACAL, the affected individual should be referred to the Health Center as soon as possible. Additional bioassay measurements shouid be made following a regimen prescribed by an internal dosimetrist. until all measurements necessary to complete the intake/dose assessment have been made. However, if any of the follow-up bioassay measurements contirm that the exposure is likely to exceed 100 millirem, the Plant Shift Superintendent's Office (574-7172) must be notified so that an Occurrence Report may be initiated. Pages 18 and 19 of Attachment I of DOE Order 5000.3B must be used to categorize the occurrence.

Individuals and their supervisors are notified of the results of special dose assessments as soon as they have been completed. Internal dosimetry requests that supervisors go over the results of the dose assessment with their empioyee, that both of them sign the assessment. and that the supervisor return it to Heaith Physics.

\subsection{Estimating Dose Equivalents}

Once an intake estimate has been obtained. it is usually easy to convert it into an estimate of dose equivalent. This conversion can normally be performed using a readily available dose conversion factor (DCF). For intakes by ingestion, and for inhalation intakes of $1 \mu \mathrm{m}$ AMAD aerosols which can be described by the standard ICRP-30 Lung model (Classes D, W, and $Y$ ), intake estimates can be converted into estimates of dose equivalent using the DCFs provided in Federal Guidance Report No. 11, "Limiting Values of Radionuclide Intake and Air Concentration and Dose Conversion Factors For ininaiation Submersion, and ingestion" (EPA88). For aerosois with AMADs other than $1 \mu \mathrm{m}$, the computer code DFINT.EXE (EC91) can be used to generate DCFs. For class $Q$, the Specific Effective Energy (SEE) values supplied in the Supplement to ICRP 30 and the NODS (number of 
disintegrations) for inhaled class $Q$ uranium generated with INDOS were used to determine a DCF (See Y/DQ-39). This DCF was determined to be 2.1E-06 Sv/Bq. When DOSEXPRT nuclide files became available for class $Q$, this software was also used to calculate a DCF. The DCF calculated by DOSEXPRT is identical to the one above.

DOSEXPRT does not generate dose estimates for direct uptakes. DCFs for uptakes can be calculated using CINDY. A DCF of $1.5 \mathrm{E}-06 \mathrm{~Sv} / \mathrm{Bq}$ for effective dose equivalent from uranium uptakes was calculated using this software. This value agrees well with a DCF of $1.4 \mathrm{E}-06 \mathrm{~Sv} / \mathrm{Bq}$ for uranium uptakes determined using SEE values and NODS. CINDY-generated dose equivalent per unit uptake values will be used for estimates of dose equivalent due to uptakes.

\subsection{Reporting Dose Equivalent Estimates}

DOSEXPRT generates estimates of dose equivalent (along with its intake estimates) for all uranium intakes (ingestion and inhalation) of significance at $\mathrm{Y}-12$ (Classes $\mathrm{D}, \mathrm{W}, \mathrm{Y}, \mathrm{Q}$, for inhalation. and soluble or insoluble for ingestion). Almost all of the dose equivalent data reported is generated by DOSEXPRT. Special dose assessments are performed for workplace and bioassay incidents, and the results of these assessments are reported to the individuais (through their supervisors) invoived a. soon as they become availabie. However. unless the results of a dose assessment indicate that an individual may have received $\geq 100$ milirem CEDE, these resuits are not reported to DOE until the end of the year. The results are then reported to DOE as part of the REIRS report generated annually (for all intakes, both chronic and acute). DOSEXPRT was designed to heip prepare this report. Besides generating several output files that can be used by a reviewer to examine results, DOSEXPRT also generates a file which is specifically intended to be input into the database where these annual dose assessments are stored. This means that all dosimetry data generated by DOSEXPRT is tranfferred to the database directly, greaty limiting the chance of himan error.

As stated in the previous chapter, when DOSEXPRT-generated intakes differ by more than $50 \%$ for acute intakes which will result in a CEDE of less than 100 millirem, or by more than $25 \%$ for intakes 
which will result in a CEDE of more than 100 millirem, an intake assessment will be performed using CINDY and INDOS, with the higher intake estimate recorded. As stated eariier in this chapter, DOSEXPRT also does not generate estimates of dose equivalent for uptakes.

When the DOSEXPRT intake estimate is not used (or unavailable as in the case with uptakes), it becomes necessary to generate the effective and organ dose equivalents manually. These doses can be determined by multiplying the intake estimate (from CINDY or INDOS) by the appropriate DCF. In order for these doses to be reporred to DOE (and stored with the other dosimetry recoras), they are entered by hand into the database (Segment 28 of the OHIS database PROD). 


\section{Chapter Five \\ Biokinetic Models For Inhaled Uranium}

\subsection{Metabolic Model For Inhaled Uranium Aerosols}

Biokinetic models have been developed which give a mathematical description of the movement of radionucides through the human system from intake to excretion. These models are an integrai part of a program designed to evaluate bioassay data. to calculate dose. and to devise a responsive screening schedule for radiation workers. The material in this section is specific to the case of uranium aerosois generated in a variety of processing and production operations at the Y-12 Plant.

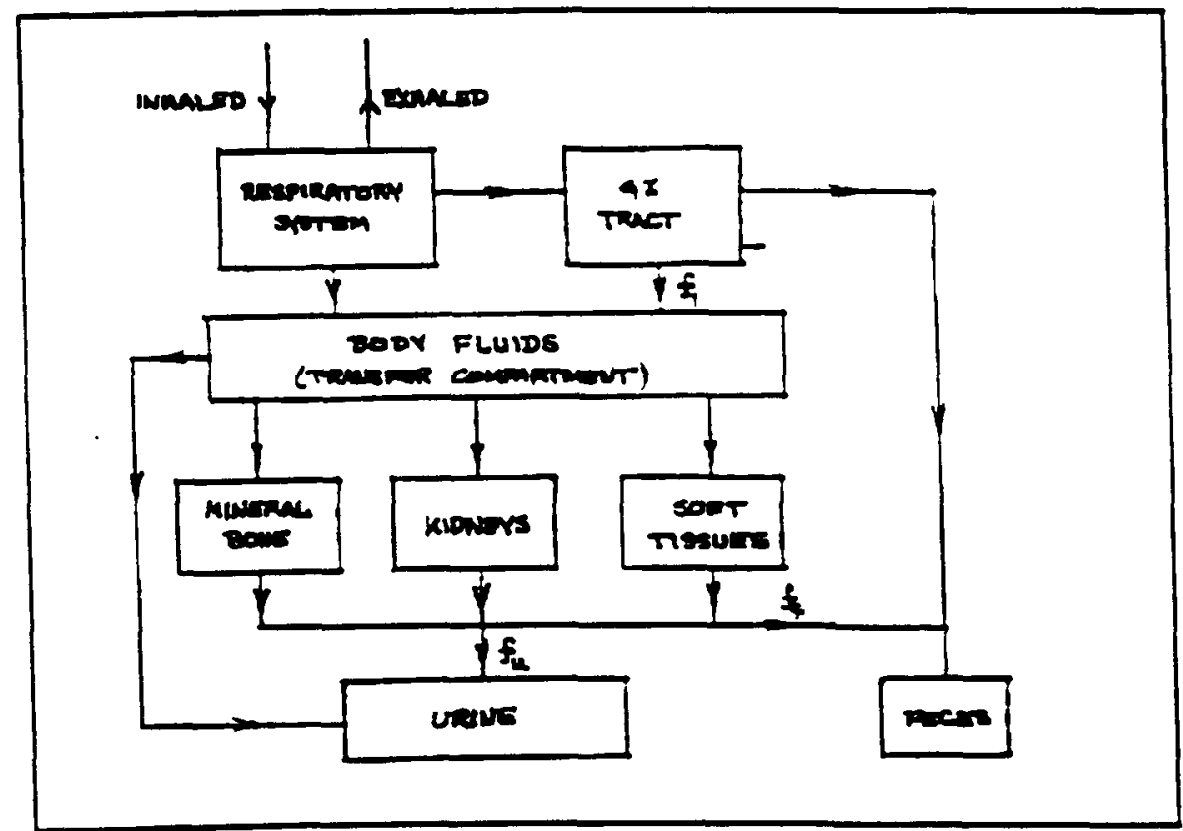

Figure 5-1 ICRP Metabolic Model For Inhaled Uranium Aerosols
The ICRP model for inhaled uranium aerosols is shown in Figure 5-1. Part of an inhaled aerosol is deposited in the respiratory tract and the remainder is exhaled. From the respiratory tract. part of the activity goes into the body fluids (transfer compartment) and part to the GI tract. A fraction, $f_{1}$, of the material transiocated to the GI tract is absorbed into the body fluids: the remainder goes to fecal excretion. Values of $f_{1}$ depend on uranium soiubility. Uranium $f_{1}$ values are summarized in Table 5-1. The body fluids distribute activity to systemic organs and tissues. For uranium, the tissues and organs of importance are the mineral bone, the kidneys, and soft tissues; the 
latter being treated collectively. The quantity $f_{u}$ is the fraction of systemic excretion that occurs via the urine, and $f_{f}=1-f_{a}$ is the fraction that occurs via the feces. In the standard systemic retention function for uranium, described by the ICRP (ICRP30, ICRP54), all systemic activity excretion is assumed to occur via the urine $\left(f_{v}=1, f_{f}=0\right)$.

Table 5-1 Inhalation Class for Uranium Compounds and Fraction $f_{1}$ from GI Tract to Body Fluids (ICRP54).

\begin{tabular}{|c|c|c|}
\hline Chemical Form & Class & $\mathrm{f}_{1}$ \\
\hline $\mathrm{UF}_{6}, \mathrm{UO}_{2} \mathrm{~F}_{3}, \mathrm{UO}_{2}\left(\mathrm{NO}_{3}\right)_{2}$ & $\mathrm{D}$ & 0.05 \\
\hline $\mathrm{UO}_{3}, \mathrm{UF}_{4}, \mathrm{UCl}_{4}$ & $\mathrm{~W}$ & 0.05 \\
\hline $\mathrm{UO}_{3}, \mathrm{U}_{3} \mathrm{O}_{8}$ & $\mathrm{Y}$ & 0.002 \\
\hline
\end{tabular}

\subsection{Deposition and Retention in Respiratory System}

The ICRP-30 model for the respiratory system is shown in Table 5-2. This system is divided into three regions designated N-P (nasal passage), T-P (trachea and bronchial tree), and P (pulmonary parenchyma). The initial deposition of inhaled material in the three regions is specified by the fractions $D_{\text {N.P. }}, D_{T-p}$, and $D_{p}$. The value of the deposition fractions as functions of Activity Median Aerodynamic Diameter (AMAD) are given in ICRP Publications (ICRP30, ICRP54). For exampie, for an aerosol having the "default" value $A M A D=1 \mu \mathrm{m}$, the values are $D_{\text {N.P }}=0.30, D_{\text {T.B }}=0.08$, and $D_{P}=0.25$; the fraction 0.37 is exhaled. Measurements made at the $Y-12$ Plant show that the aerosols are characterized by an $8 \mu \mathrm{m}$ AMAD (See Y/DQ-39). The corresponding deposition fractions are $D_{\text {N.P }}=0.841, D_{\text {T.B }}=0.080$, and $D_{p}=0.062$ (ICRP54, p. 8 ). For these larger partictes. most of the actrvity is deposited in the N-P region; about $2 \%$ is assumed to be exhaled. 
Table 5-2 Parameters for the ICRP Respiratory System for Class $Q$

\begin{tabular}{|c|c|c|c|c|c|c|}
\hline \multirow{2}{*}{ Region } & \multirow{2}{*}{$\begin{array}{c}\text { Deposicion } \\
\text { Fractions } \\
D_{\text {mim }} \\
(8 \mu \mathrm{m} \text { AMAD) }\end{array}$} & \multirow{2}{*}{ Compartment } & \multicolumn{4}{|c|}{ Class $\mathbf{Q}$} \\
\hline & & & $\begin{array}{l}\text { Modif } \\
\text { T(d) }\end{array}$ & $\begin{array}{c}\text { (0\%) } \\
\text { F }\end{array}$ & $\begin{array}{r}Y \\
T(d)\end{array}$ & 6) $\mathrm{F}$ \\
\hline $\mathbf{N}-\mathbf{P}$ & 0.841 & $\mathrm{a}$ & $\begin{array}{l}0.01 \\
0.40\end{array}$ & $\begin{array}{l}0.1 \\
0.9 \\
\end{array}$ & $\begin{array}{l}0.01 \\
0.40\end{array}$ & $\begin{array}{l}0.01 \\
0.99\end{array}$ \\
\hline$T-B$ & 0.080 & $\begin{array}{l}\mathrm{c} \\
\mathrm{d}\end{array}$ & $\begin{array}{l}0.01 \\
0.20\end{array}$ & $\begin{array}{l}0.5 \\
0.5 \\
\end{array}$ & $\begin{array}{l}0.01 \\
0.20\end{array}$ & $\begin{array}{l}0.01 \\
0.99 \\
\end{array}$ \\
\hline $\mathbf{P}$ & 0.062 & $\begin{array}{l}\text { e } \\
\text { f } \\
g \\
\mathrm{~h}\end{array}$ & $\begin{array}{l}120 \\
1.0 \\
120 \\
120 \\
\end{array}$ & $\begin{array}{l}0.15 \\
0.40 \\
0.40 \\
0.05 \\
\end{array}$ & $\begin{array}{l}500 \\
1.0 \\
500 \\
500 \\
\end{array}$ & $\begin{array}{l}0.05 \\
0.40 \\
0.40 \\
0.15 \\
\end{array}$ \\
\hline $\mathrm{L}$ & $\begin{array}{c}\text { no } \\
\text { direct } \\
\text { deposition }\end{array}$ & $\begin{array}{l}\mathrm{i} \\
\mathrm{j}\end{array}$ & $\begin{array}{l}120 \\
\text { n.a. }\end{array}$ & $\begin{array}{l}1.0 \\
\text { n.2. }\end{array}$ & $\begin{array}{c}1000 \\
\infty\end{array}$ & $\begin{array}{l}0.9 \\
0.1 \\
\end{array}$ \\
\hline
\end{tabular}

For different chemical forms ot a radionuciide. ICRP classities aerosois as D. W, or $\mathrm{Y}$, according to biological clearance times from the puimonary regions. ICRP 54 (ICRP54) considers $\mathrm{U}_{3} \mathrm{O}_{8}$ nominally as a class $Y$ compound. The extensive experience with personnel monitoring measurements and their interpretation at the Y-12 Plant is described in Y/DQ-39. The data consistently show that retention and excretion of uranium in most cases are best described as a combination of class $Y$ and "modified class W" materials. Modified class W corresponds to the usual ICRP 54 class W parameters with the $50 \mathrm{~d}$ clearance half-times increased to $120 \mathrm{~d}$. This combination, which is designated class "Q", corresponds to $90 \%$ modified class $\mathrm{W}$ and $10 \%$ class $\mathrm{Y}$ with the compartmental fractions and retention half-times shown in Table 5-2. Further details are given in Y/DQ-39.

The three regions of deposition in the respiratory model are further subdivided into 8 compartments, a - h, as shown in Figure 5-2. Compartments a, $c$, and e are associated with absorption processes and 
compartments $b, d, f$, and $g$ are associated with the physical transport of particles from the respiratory system to the GI tract (e.g., by ciliary action and swallowing). Compartment h transfers material to the lymph nodes, compartments $i$ and $j$.

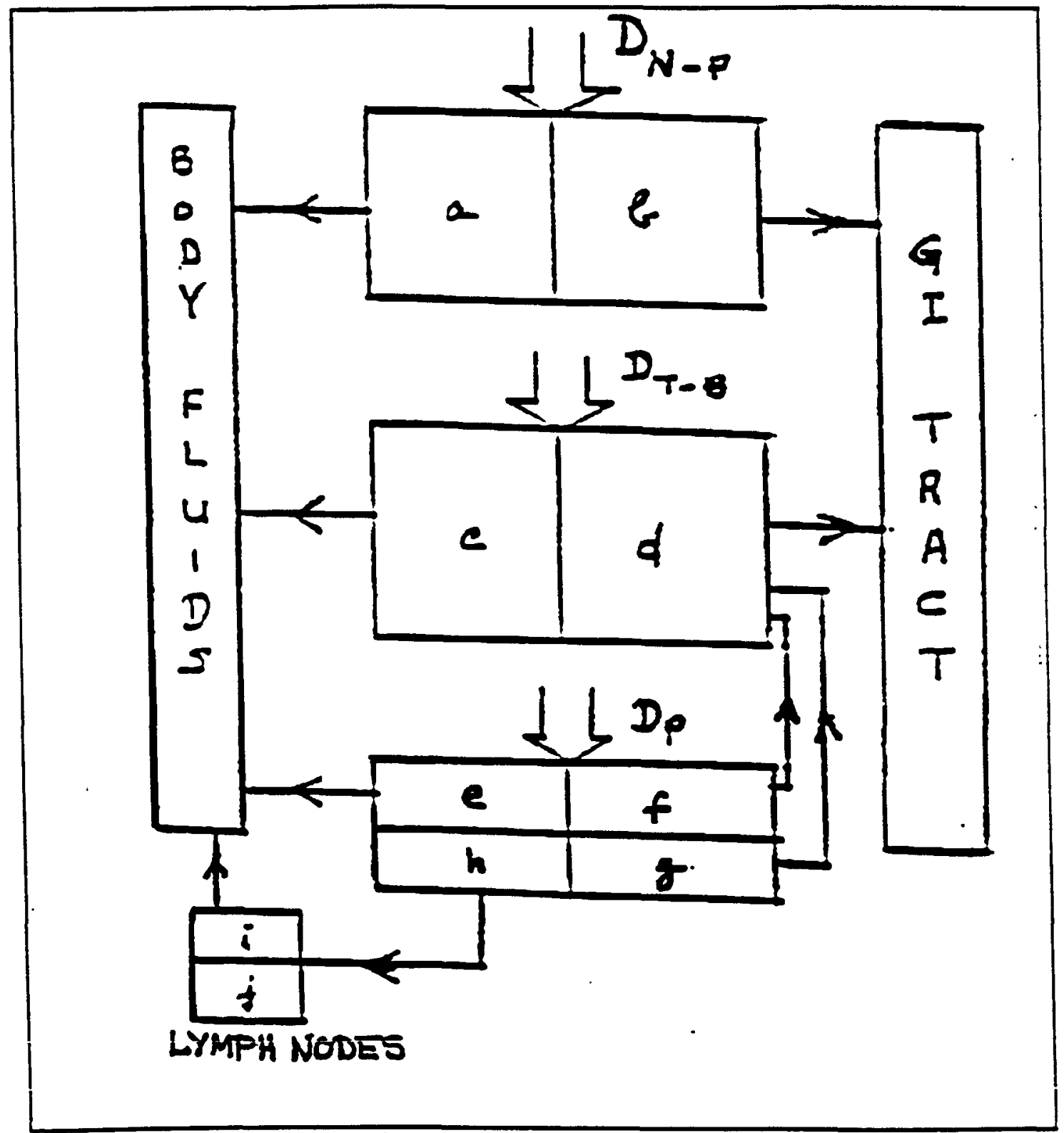

Figure 5-2 ICRP Model of Respiratory System 


\subsection{Systemic Retention and Excretion}

After initial deposition in the lungs, activity is transferred directly to the GI tract and to the body fluids, or transfer compartment, as shown in Figure 5-1. In the ICRP model, the retention half-time of a material in the transfer compartment is $0.25 \mathrm{~d}$. This time is negligible compared with the radiological half-life of uranium. Therefore. the activity in the body fluids is assumed to be transferred immediately to the kidney, bone. soft tissues, and urine.

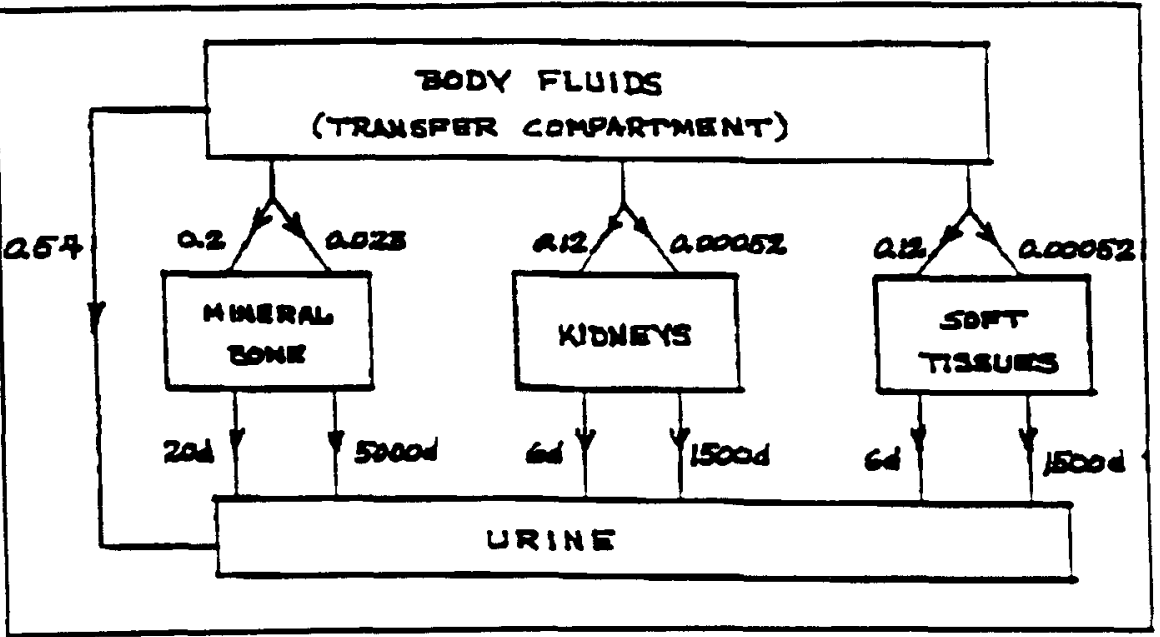

Figure 5-3 ICRP Systemic Model For Uranium
The systemic model for uranium is shown in Figure 5-3 (DE88). From the body fluids (or transfer compartment), the fraction 0.54 is excreted directiy into the urine. The fractions 0.2 and 0.023 go to mineral bone. where they are retanned with nicrabolic haiftimes. $T$, of $20 \mathrm{~d}$ and $5000 \mathrm{~d}$,

respectively. The fractions 0.12 and 0.00052 go to kidneys with $\mathrm{T}=6 \mathrm{~d}$ and $\mathrm{T}=1500 \mathrm{~d}$, and 0.12 and 0.00052 go to soft tissues of the body with $T=6 \mathrm{~d}$ and $1500 \mathrm{~d}$.

The systemic retention of uranium as a function of the time. $t$, in days since uptake is described by the equation (ICRP54. p. 209)

$$
r_{B S}^{a}(t)=\sum_{i} a_{i} \exp \left(-0.693 t / b_{i}\right)
$$

where the coefficients $a_{i}$ and $b_{1}$ are given in Table 5-3 (see also Figure 5-3). Here $r_{B, s}(t)$ represents the biological (B), systemic (s) activity retained per unit uptake (superscript a) of activity as a function 
of the time $t$ after uptake.

Table 5-3 Coefficients for Calculating Systemic Retention and Urinary Excretion

\begin{tabular}{|c|c|c|c|}
\hline $\begin{array}{c}\text { BODY FLUIDS TO } \\
\text { URINE VIA }\end{array}$ & $i$ & $a_{i}$ & $b_{i}$ (days) \\
\hline \hline DIRECT & 1 & 0.54 & 0.25 \\
\hline MINERAL & 2 & 0.2 & 20 \\
BONE & 3 & 0.023 & 5000 \\
\hline KIDNEYS & 4 & 0.12 & 6 \\
& 5 & 0.00052 & 1500 \\
\hline SOFT & 6 & 0.12 & 6 \\
TISSUES & 7 & 0.00052 & 1500 \\
\hline
\end{tabular}

The activity excretion rate into the urine (subscript $u$ ) is given by the negative of the time derivative of $r_{\mathrm{B}}$ (ICRP54, p. 210):

$$
e_{B x}^{a}(t)=\sum_{t}\left(0.693 a / b_{i}\right) \exp \left(-0.693 t / b_{i}\right)
$$

With the models presented in this chapter it is possible to completely describe the translocation of inhaled or ingested uranium from intake to excretion. This description takes its form in simuitaneous differential equations which may be solved to yield the quantities commoniy used in intake and dose assessments, such as $\operatorname{IRF}(t)$ values for acute and chronic intake and the number of disintegrations (NODS) expected in some organ (or actually mathematical compartment) during a given time period (e.g., one or fifty years). 


\section{BIBLIOGRAPHY}

ACGIH68 American Conference of Governmental Industrial Hygienists. Thresnold Limit Values in airborne contaminants for 1968, recommended and intended values. St. Louis, MO.

ACGIH83 American Conference of Governmental Industrial Hygienists. Threshold Limit Values for chemical substances and physical agents in the work environment with intended changes for 1983-84. Cincinnati. OH.

ANSI92 American National Standards Institute. Performance Criteria For Radiobioassay, ANSI N13.30, 1992, New York. NY.

DE88 Health Physics Manual of Good Practices for Uranium Faciiities. DE88-013620. National Technical Information Service. U. S. Department of Commerce. Springfield, VA 22161, June 1988.

DOE88 Radiation Protection for Occupational Workers, Order DOE 5480.11. U. S. Department of Energy, Washington. DC. June 1992.

DOE91a Draft Implementation Guide 4.1X, Internal Dosimetry Program. Revision 1, U. S. Department of Energy, (Nov.. 1991).

DOE91b Technical Manual 4.1X, Draft DOE Technical Manual for Internal Dosimetry Programs, U. S. Department of Energy (1991).

EPA88 K. F. Eckerman. A. B. Wolbarst. and A. C. B. Richardson. Limiring Values of Radionuclide Intake and Air Concentration and Dose Conversion Factors For Inhalation, Submersion and Ingestion - Federal Guidance Report Number 11, Office of Radiation Protection Programs. U.S. Environmental Protection Agency, (Sept., 1988).

EC91 K F. Eckerman, $A$ Code to Preview the Dosimetric Data of ICRP Publication 30, Parts 1-4 (DFint Code, Version Kiawah), Oak Ridge National Laboratory, Oak Ridge, TN, February 1991.

ICRP23 Report of the Task Group on Reference Man, ICRP Publication 23, Pergamon Press, Oxford (1975).

ICRP30 Limits for Intakes of Radionuclides bv Workers. ICRP Publication 30, Pergamon Press, New York. NY (1979).

ICRP54 Individual Monitoring for Intakes of Radionuclides by Workers: Design and Interpretation, ICRP Publication 54, Pergamon Press. Oxford (1988). 
ICRP66 ICRP Group on Lung Dynamics, "Deposition and Retention Models for Internal Dosimetry of the Human Respiratory Tract," Health Phys. 12 173-207 (1966).

KE92 R. A. Kennedy and D. L. Strenge, Code For Internal Dosimetry (CINDY Version 1.2), Pacific Northwest Laboratory, July 1992, Richland, WA.

NCRP87 National Council on Radiation Protection and Measurement, Use of Bioassay Procedures for Assessment of Internal Radionuclide Deposition, NCRP Report No. 87, 1987.

NR4884 E. T. Lessard, et al., Interpretation of Bioassay Measurements. NUREG/CR-4884, BNLNUREG-52063, February 1987.

OSHA74 U. S. Code of Federal Regulations, "Occupationai Safety and Heaith Standards." Title 29 Part 1910.1000, U. S. Government Printing Office. 1974, Washington D.C.

RC92 Radiological Control Manual, DOE N 5480.6. U. S. Department of Energy, Washington. DC (1992).

SC64 L. M. Scott, "Excretion of Uranium from Mixed Exposures under Industrial Conditions," Health Phys. 10, 479-481 (1964).

SK86 Skrable Enterprises. INDOS-internal dosimetry computer programs, Chelmsford. MA (1986).

SD85 H. Schieferdecker, H. Dilger, H. Doerfel, W. Rudolph, and R. Anton. "Inhaiation of U Aerosois from UO 2 Fuel Element Fabrication." Health Phys. 48. 29-48 (1985).

WA92 R. C. Ward, and K. F. Eckerman, DOSEXPRT - A Bioassay Dosimetry Code for Martin Marietta Energy Systems, Inc., ORNL/TM-11857, Oak Ridge National Laboratory, Oak Ridge, TN, April 1992

WS79 C. M. West, L. M. Scott, and N. B. Schultz, "Sixteen Years of Uranium Personnel Monitoring Experience - in Retrospect," Heaith Phys. 36, 665-669 (1979). 